\title{
The effectiveness of extracorporeal shockwave therapy in common lower limb conditions: a systematic review including quantification of patient- rated pain reduction
}

\author{
Vasileios Korakakis, ${ }^{1,2,3}$ Rodney Whiteley, ${ }^{1}$ Alexander Tzavara, ${ }^{2}$ \\ Nikolaos Malliaropoulos ${ }^{4,5,6}$
}

- Additional material is published online only. To view please visit the journal online (http://dx.doi.org/10.1136/ bjsports-2016-097347).

${ }^{1}$ Aspetar, Orthopaedic and Sports Medicine Hospital, Doha, Qatar

${ }^{2}$ Hellenic Orthopaedic

Manipulative Therapy Diploma (HOMTD), Athens, Greece

${ }^{3}$ Faculty of Physical Education and Sport Sciences, University of Thessaly, Trikala, Greece

${ }^{4}$ Sports and Exercise Medicine Clinic, Thessaloniki, Thessaloniki, Greece

${ }^{5}$ Rheumatology Department, Sports Clinic, Barts Health NHS Trust, London, UK

${ }^{6}$ European Sports Care, London, UK

\section{Correspondence to}

Mr Vasileios Korakakis, Aspetar, Orthopaedic and Sports

Medicine Hospital, Doha, PO

Box 29222, Oatar:

Vasileios.Korakakis@aspetar. com

Received 12 December 2016 Revised 9 April 2017 Accepted 7 June 2017 Published Online First 27 September 2017
Check for updates

To cite: Korakakis $V_{\text {, }}$ Whiteley R, Tzavara A, et al. Br J Sports Med 2018:52:387-407.

\begin{abstract}
Objective To evaluate extracorporeal shockwave therapy (ESWT) in treating Achilles tendinopathy (AT), greater trochanteric pain syndrome (GTPS), medial tibial stress syndrome (MTSS), patellar tendinopathy (PT) and proximal hamstring tendinopathy (PHT).

Design Systematic review.

Eligibility criteria Randomised and non-randomised studies assessing ESWT in patients with AT, GTPS, MTSS, PT and PHT were included. Risk of bias and quality of studies were evaluated.

Results Moderate-level evidence suggests (1) no difference between focused ESWT and placebo ESWT at short and mid-term in PT and (2) radial ESWT is superior to conservative treatment at short, mid and long term in PHT. Low-level evidence suggests that ESWT (1) is comparable to eccentric training, but superior to wait-and-see policy at 4 months in mid-portion AT; (2) is superior to eccentric training at 4 months in insertional AT; (3) less effective than corticosteroid injection at short term, but ESWT produced superior results at mid and long term in GTPS; (4) produced comparable results to control treatment at long term in GTPS; and (5) is superior to control conservative treatment at long term in PT. Regarding the rest of the results, there was only very low or no level of evidence. 13 studies showed high risk of bias largely due to methodology, blinding and reporting.
\end{abstract}

Conclusion Low level of evidence suggests that ESWT may be effective for some lower limb conditions in all phases of the rehabilitation.

\section{INTRODUCTION}

Extracorporeal shockwave therapy (ESWT) is often used in the management of common lower limb conditions. These include Achilles tendinopathy ${ }^{1-15}$ (AT), greater trochanteric pain syndrome ${ }^{16} 17$ (GTPS), medial tibial stress syndrome ${ }^{18-20}$ (MTSS), patellar tendinopathy ${ }^{10} 21-30$ (PT) and proximal hamstring tendinopathy ${ }^{31}$ (PHT).

As with primary research studies, systematic reviews vary greatly in quality and clarity of reporting. With the aim to address suboptimal reporting and improve the quality of systematic reviews, guidelines have been published, such as the Preferred Reporting Items for Systematic reviews and Meta-analyses (PRISMA) statement. ${ }^{32}$ Recently, several systematic reviews of the effectiveness of ESWT have been published which did not adhere to these recommendations. ${ }^{33-35}$ In addition, in systematic reviews evaluating ESWT effectiveness several types of biases can be identified. Selective reporting of complete studies (eg, publication bias) and inclusion of only studies in English language (eg, language bias) are the most frequent types of bias 36 found in the majority of these reviews ${ }^{33-35}$ 37-39 while a minority of them meet these quality requirements. ${ }^{40}$ It is also noted that a relatively large body of evidence is mainly driven and established by the quality assessment tools. The arbitrary selection of quality assessment tools (ie, risk of bias tool, Downs and Black checklist, Jadad score), along with poor reporting ${ }^{41}$ and differences in inclusion and exclusion criteria, leads systematic reviews to inconsistent conclusions and recommendations. ${ }^{343742}$

Taking this into account, this review intended to evaluate the short term ( $\leq 3$ months), mid-term ( 3 to $<12$ months) and long term $(\geq 12$ months) effectiveness of ESWT in the treatment of AT, GTPS, MTSS, PT and PHT by following published guidelines, robust quality assessment criteria, well-described measures of treatment effect and an established approach for quality of evidence and recommendations. A secondary objective was to document, where possible, the specifics of successful ESWT parameters in the conditions under investigation.

\section{MATERIALS AND METHODS}

We adhered to the PRISMA guidelines ${ }^{32}$ in search strategy and reporting, and followed guidance of Cochrane Handbook for Systematic Reviews ${ }^{36}$ for the preparation of this intervention review.

\section{Eligibility criteria}

Types of studies

We included randomised and non-randomised studies at the initial selection. Criteria for qualitative and quantitative synthesis are stated below. No limit on language or publication year was imposed to minimise language and publication bias. No minimal duration of follow-up was considered for inclusion.

Type of participants

The population consists of patients suffering from AT, GTPS, MTSS, PT and PHT. We included adult patients of both sexes, involved in all types of activities, and we set no limit for duration of symptoms. 


\section{Types of intervention}

We included studies on radial or focused ESWT, high or low energy, or studies where ESWT was used as a monotherapy or as an additive intervention.

\section{Types of outcome measures}

The effectiveness of ESWT was evaluated in terms of improvement in function, patient-perceived recovery and pain reduction. Follow-up was categorised into short term ( $\leq 3$ months), mid-term ( 3 to $<12$ months) and long term ( $\geq 12$ months), as recommended by the 2009 updated Method Guidelines for Systematic Reviews of Cochrane group. ${ }^{36}$

Eligible studies evaluated at least one of the main clinically relevant outcome measures using a valid instrument. The only secondary outcome that was used was time to recovery where non-condition-specific scales were available (ie, MTSS) and the predefined primary outcome measures were compared, as mentioned below.

Previous systematic reviews 3435374243 of ESWT in the management of lower limb conditions have typically reported treatment effects in terms of standardised mean differences (SMDs) or were unable to pool data due to heterogeneity of studies. In addition, we suggest that treatment effects need to be presented in with reference to the patient's perspective, and as such we propose that outcomes should be also reported in patient-specific terms ${ }^{44}$ (rather than statistically derived outcomes which may or may not be associated with the patient's experience). The patient's experience of change in pain ('improvement' or 'worsening') is seen to vary according to their baseline levels of pain such that a reduction of one point on a pain scale is perceived differently if your baseline level is 9 or 3 , for example. Two approaches are documented attempting to overcome these limitations. Some researchers advocate using a percentage reduction as denoting clinically meaningful change in pain as, for example, Ostelo et $a l .^{45}$ Alternately Farrar et $a l^{44}$ examined both the numeric rating scale (NRS) pain change and the individual patient's rating of the change in pain on a seven-point Likert scale. This scale ranged from 'very much improved' to 'very much worsened'. They showed that the patient rating was not distributed equally across the categorisations when adjusting for the baseline level of pain.

Accordingly, this systematic review also aims to document the outcomes of ESWT and evaluate the effect in terms of the patient-reported benefit. To accomplish that, we considered absolute change in pain when adjusting for baseline levels of pain (see measures of treatment effect section). ${ }^{44}$ It should be recalled that in the presence of high enough sample size and/or low enough variance, even a reduction in pain of $0.5 / 10$ can be considered statistically significant when this is clearly clinically meaningless. Further in the presence of a high baseline level of pain, such a reduction is actually perceived by the patient as a clinical worsening after an intervention, ${ }^{44}$ hence reporting these changes according to patient rating is seen as more clinically applicable.

Primary outcomes

- functional disability (eg, Victorian Institute of Sports Assessment-achilles questionnaire (VISA-A), ${ }^{46}$ Victorian Institute of Sports Assessment-patella questionnaire (VISA-P) ${ }^{47}$ )

- self-perceived recovery

- pain reduction in visual analogue scale (VAS) or NRS

\section{Information sources and search methods}

A systematic search was undertaken on 15 August 2016 adhering to the PRISMA guidelines ${ }^{32}$ using the following databases:
MEDLINE, CINAHL Plus, EMBASE, Web of Science and the Cochrane Library. Grey literature was searched via OpenGrey as were the following clinical trial registries: EU Clinical trials Register, Clinical Trials.gov, WHO International Clinical Trials Registry Platform and Australian New Zealand Clinical Trials registry. The basic search strategy is presented in online supplementary appendix 1 .

Additionally, reference lists and citation tracking results were also reviewed. Systematic reviews were not included or assessed for quality, but were examined for possible references.

\section{Study selection}

Two reviewers independently identified relevant titles and abstracts in two different search sessions. A third reviewer was consulted if consensus was not reached and full text was obtained if necessary.

\section{Data collection, extraction and analysis}

We categorised retrieved studies into three groups: randomised controlled trials (RCTs), non-randomised controlled studies (both used in quantitative synthesis) and prospective/retrospective non-controlled trials (used only in qualitative evaluation).

All data describing study characteristics such as study design, quality and risk of bias assessment, demographics and numbers of participants, interventions and co-interventions, treatment protocol, primary and secondary outcomes, follow-up time and main results were extracted and presented.

Data were entered into and analysed using Review Manager V.5.3 statistical software of the Nordic Cochrane Collaboration. ${ }^{48}$

\section{Assessment of quality and risk of bias}

Two independent reviewers assessed risk of bias using the criteria advised by the Cochrane Review Group for evaluation of RCTs. ${ }^{36}$ As this list is not suitable for assessment of non-randomised studies, in agreement with the recommendations provided by the Cochrane non-randomised studies methods group, ${ }^{49}$ we selected a modified Downs and Black checklist ${ }^{50}$ to evaluate the non-randomised studies. Both lists are designed to assess the internal validity of the studies. Justification for each selection/scoring in both risk of bias tool and Downs and Black checklist is presented in supplementary appendices 2 and 3 . An estimate of correlation between these tools in terms of study quality was calculated.

Risk of bias was assessed with a modification of the Cochrane Risk of Bias tool. The tool used expanded the 7 main domains and comprises 13 items; however for ESWT, it is currently impractical to expect blinding of participants or care providers. Accordingly, arbitrarily the review authors rated studies as having low risk of bias if at least seven of the criteria were met and the study had no serious flaws (ie, excessive drop-out rate, extremely small sample size $-<15$ per group). Descriptions of the scoring and reasons are available in online supplementary appendix 2 .

The modified Downs and Black checklist consists of 27 items, with a total possible score of 28 for randomised and 25 for non-randomised studies and has been proven valid and consistent among reviewers. ${ }^{50}$ In the present version of the checklist, we modified the scoring of item 27 that refers to the power of the study. Instead of rating according to an available range of study powers, we rated whether the study or not performed power calculation. Accordingly, the maximum score for item 27 was 1 (a power analysis was conducted) instead of 5 and thus the highest possible score for the checklist was 28 (instead of 32). Downs and Black score ranges were given corresponding quality levels as previously reported ${ }^{51}$ : excellent (26-28), good 
(20-25), fair (15-19) and poor $(\leq 14)$ (see online supplementary appendix 3$)$.

In non-randomised trials, the use of allocation mechanism predisposes outcomes to be subject to confounding. The characteristics considered for confounding such as age, gender, duration of symptoms and baseline symptoms were taken into consideration in heterogeneity assessment in order to pool data. ${ }^{49}$

The review authors discussed differences in scoring of the risk of bias and Downs and Black assessment during consensus meeting and consulted a third reviewer when necessary.

\section{Measures of treatment effect, assessment of heterogeneity and data synthesis}

Differences on the primary outcome measures between the ESWT and control groups and the patient rating of clinical effectiveness were defined as treatment effects.

We presented comparisons of continuous data as mean differences (MDs) with corresponding CIs. Continuous data were compared directly or by calculation of SMDs if outcome measures were not directly comparable due to different measurement scales used. For dichotomous data, the effect measure calculated was ORs with 95\% CIs.

We assessed the included studies first for the more important clinical heterogeneity and then for statistical heterogeneity. ${ }^{52}$ Clinical heterogeneity was evaluated for variability in duration of symptoms, patient age and baseline pain and/or functional characteristics with individual assessments examining group means and variance to decide for a combined quantitative analysis. When we judged studies to be clinically homogenous, we tested statistical homogeneity. If there were $>10$ studies available, a meta-regression was performed. ${ }^{36}$

Evaluation of heterogeneity in order to pool data was not judged only by the value of $\mathrm{I}^{2}$ statistic, as thresholds for the interpretation can be misleading. ${ }^{53}$ Since clinical and methodological diversity always occur in quantitative synthesis, statistical heterogeneity is inevitable. ${ }^{52}$ Statistical heterogeneity was assessed as follows: (1) overlap (poor or adequate) of CIs presented in forest plots $^{36}$; (2) magnitude and direction of effects ${ }^{36}$; (3) sample sizes and number of studies included (as small number of participants and/or studies included in analysis results in low power of heterogeneity test $)^{53}$; and (4) strength of evidence for heterogeneity ( $\mathrm{p}$ value from $\chi^{2}$ test or CI for $\left.\mathrm{I}^{2}\right) .^{36}$

We aimed to use minimal clinically important difference (MCID) in order to measure clinically relevant treatment effect. Unfortunately, to date there is no consensus on MCID in pain and functional outcomes in AT and PT. Finally, there is no consistent use of condition-specific outcome measures among studies, and no available condition-specific outcome measures for GTPS, MTSS and PHT at the time that these studies were conducted. The treatment effects, therefore, were measured as follows:

- We defined MCID for VISA-P a mean 15-point change and for Harris hip score (HHS) a mean 10-point change based on studies assessing clinimetric properties of the scales. ${ }^{54-56}$

- MCID for VISA-A has been reported ${ }^{57}$ to be 6.5 points; based on available data, ${ }^{58} 59$ we arbitrary increased this cut-off point to 12 points.

- We employed the methods of Overdevest et $a l^{60}$ in setting the MCID to a $30 \%$ improvement from the mean of the baseline level of pain. This corresponded to 1.5 points on a VAS and 2.0 points on an NRS for the data examined here.

To estimate the patient-rated clinical effectiveness, previously described thresholds for change in pain scores were used, with appropriate adjustment for baseline levels of pain $(6,7$ and 8/10 baseline pain). ${ }^{44}$ Since the data from the study of Farrar et $a l^{44}$ were not normally distributed, the appropriate group estimator was the median. Accordingly, treatment outcomes were classified in line with the closest median for each category. Specifically, the median values for the six categorisations of change in pain were as follows: 'much worse' $\geq+0.32 / 10$; 'minimally worse' $\leq-0.08 / 10$; 'no change' $\leq-0.20 / 10$; 'minimally improved' $\leq-1.07 / 10$; 'much improved' $\leq-2.69 / 10$; and 'very much improved' $\leq-4 \cdot 15 / 10$. We pooled results if they were judged to be sufficiently homogenous (methodologically and statistically).

We evaluated the quality of evidence using the Grading of Recommendations Assessment, Development and Evaluation (GRADE) approach. ${ }^{61}$ The adapted following criteria were used: (1) $75 \%$ of studies have low risk of bias ( $\geq 7$ items of risk of bias tool met); (2) included studies have relatively consistent findings; (3) included population adequately reflects selection criteria of the review; (4) results are based on direct and indirect comparison, as usually ESWT is not used as a monotherapy in clinical practice (studies with indirect comparison were automatically downgraded); (5) estimate of effect is sufficiently precise (CI is narrow and conclusive); and (6) analysis is free of publication bias.

Additionally, regarding non-randomised trials, ${ }^{49}$ we selected only prospective controlled studies and a priori their level of evidence was set as 'low'. All the following criteria ${ }^{49}$ were used for non-randomised studies in order to be included in quantitative synthesis: (1) reasonably resistant to biases (selection biaswithin-study and between-study differences between patients in different groups, sample representative of population, which parts of the study were prospectively designed, potential confounders; detection bias-patient-reported outcomes; attrition bias); (2) Downs and Black score > 20 (good quality); (3) relatively homogeneous with included RCTs (confounders, population, intervention, outcomes); (4) intervention and control group matched for at least age, duration of symptoms and pain and/or functional status; and (5) investigating longterm outcomes.

We used guidelines from Cochrane Collaboration Group ${ }^{36}$ to assess levels of quality of evidence (table 1). We a priori graded an outcome with only one trial as low quality, and if it also had high risk of bias the evidence was graded as very low quality. $^{61}$

Results were presented as summary tables and forest plots with total and subtotal values where applicable (see online supplementary appendix 4). Forest plots are presented only if aggregate, pooled estimates meet the predefined homogeneity criteria. If only one study with low risk of bias was found, we depicted the effect in a singular forest plot of the outcome parameter. A suggested protocol was presented where possible, based on ESWT parameters used and extracted form high-quality studies with favourable outcomes for ESWT.

\section{Additional analyses}

The robustness of our results was tested through a sensitivity analysis. We performed analyses to investigate various aspects of trial and review methodology. These included assessing the impact of (1) using solely high-quality studies with using studies of low, medium and high quality combined; (2) using fixed-effects versus random-effects models; and (3) using SMD instead of MD for pooling (see online supplementary appendix 5). 


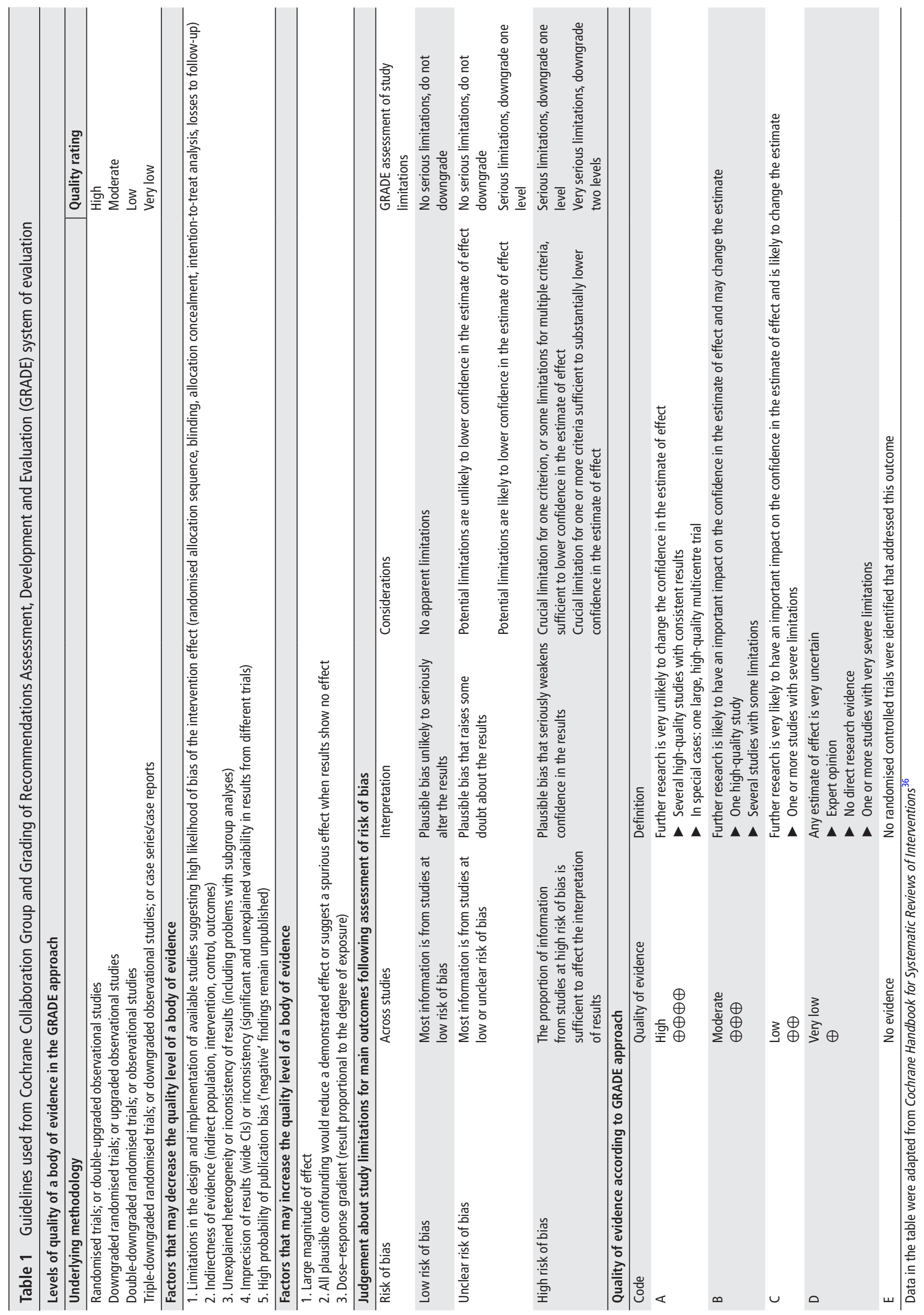




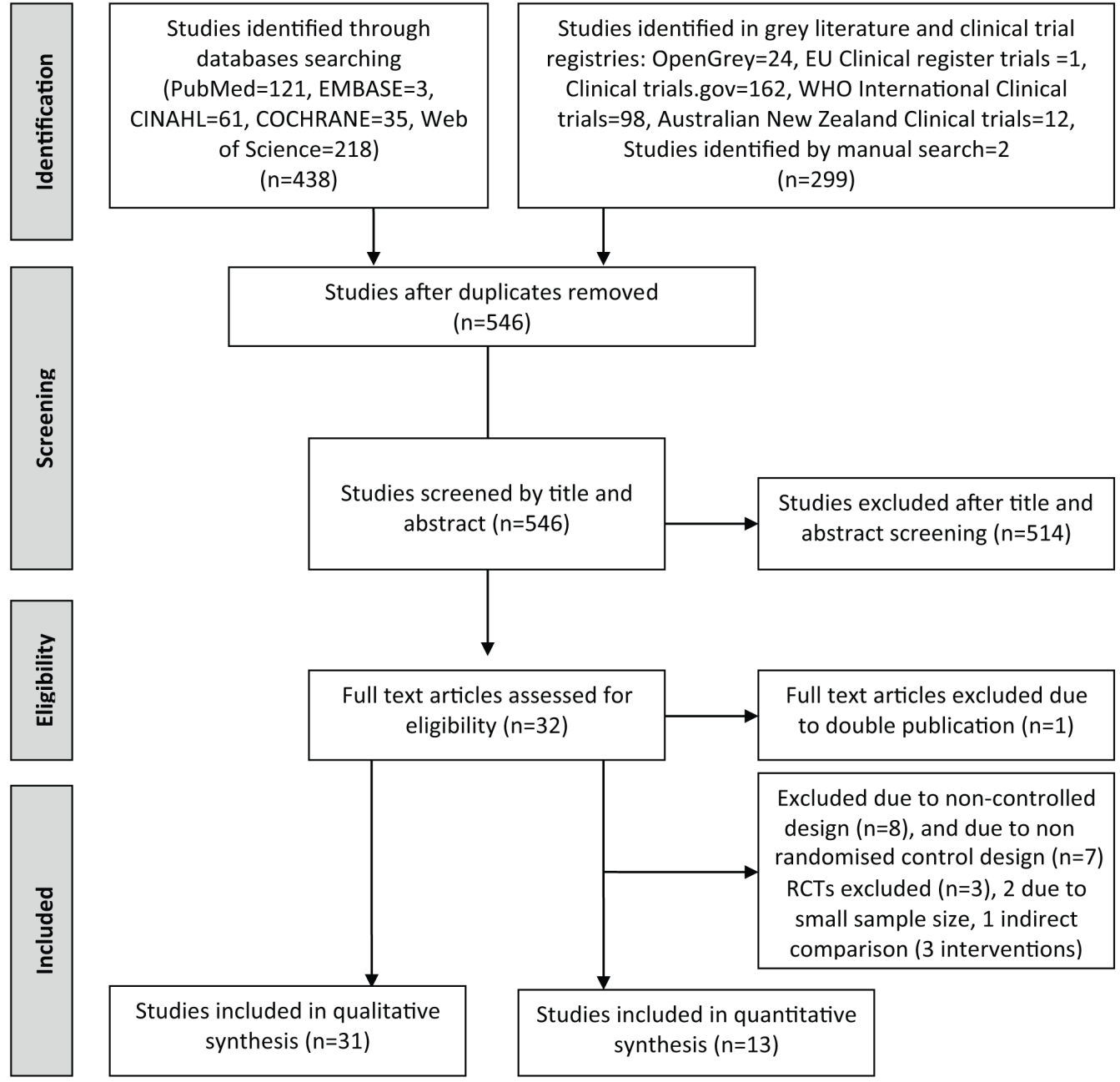

Figure 1 The Preferred Reporting Items for Systematic reviews and Meta-analyses flow diagram of study selection process.

\section{RESULTS}

\section{Results of the search}

The literature search up to 15 August 2016 yielded 736 articles and manual search added 2 studies. Once duplicates were removed, 546 studies were assessed for eligibility from the title and abstract, which revealed 32 suitable studies for quality assessment (figure 1). One study ${ }^{62}$ was excluded after full-text assessment as double publication. Agreement on article eligibility between the two reviewers was 100\% $(n=31)$.

An overview network representation of all the primary controlled studies is presented in figure 2. The diagram depicts the results of all the studies before assessment of quality and evaluation for inclusion in quantitative synthesis. The network diagram stands as an overview of all available studies that have investigated the effects of ESWT compared with other interventions in patients with lower limb pathologies.

\section{Characteristics, quality and risk of bias of included and excluded studies}

Study design, study level of evidence, risk of bias, total Downs and Black scores, sample size, age of the participants, interventions, ESWT protocol, length of follow-up, outcome measures and main results of the studies meeting the eligibility criteria for qualitative synthesis are presented inonline supplementary table 2. Thirty-one studies ${ }^{1-31}$ published between 2002 and 2016 involving a total of 1847 participants were included in qualitative analysis. Quality assessment, risk of bias and justification for selection/scoring of each individual study are presented in online supplementary appendices 2 and 3. Out of the 31 studies assessed, only 12 RCTs ${ }^{46714151725-2729-31}$ and 1 non-randomised controlled study ${ }^{16}$ met the inclusion criteria for quantitative synthesis.

\section{Risk of bias and quality assessment of included studies}

All included studies had low risk of bias, having met at least seven of the risk of bias criteria. Poor performance on the risk of bias assessment (figure 3) was the result of methodology, blinding and reporting. Assessment of the tools used showed a poor correlation between risk of bias and Downs and Black checklist $(r=0.5)$.

\section{Synthesis of results}

Patient-rated pain reduction for clinical effectiveness

To estimate the patient-rated clinical effectiveness, previously described thresholds for change in pain scores were used, with appropriate adjustment for baseline levels of pain (6, 7 and 8/10 baseline pain). ${ }^{44}$ For a clinically meaningful interpretation of results, a graphical representation of change in pain scores for ESWT and control groups for different pathologies is presented in figure 4. The cut-off points for the six categorisations of change in pain were as follows: 'much worse' $\geq+0.32 / 10$; 


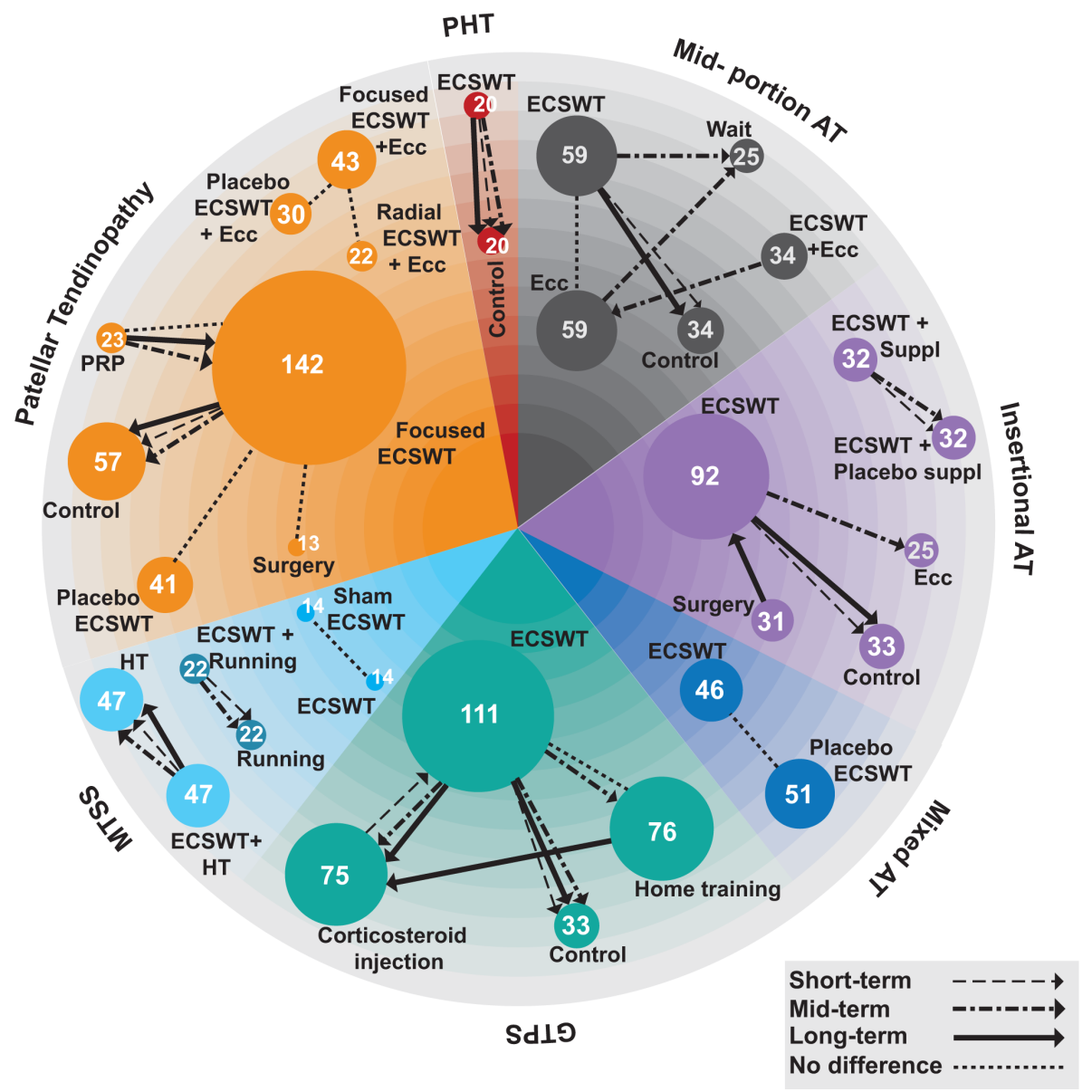

Figure 2 Network comparisons of extracorporeal shockwave therapy (ESWT) interventions for common low limb pathologies. The size of pie part represents the total number of participants having received ESWT as a primary intervention. The direction of the arrowhead on the lines (solid or dashed) indicates the intervention with known superior effect over the comparator. The different size and type of the line represent the time of follow-up (short term, mid-term and long term) as depicted in the legend of the figure. The dotted line without arrowhead represents head-to-head comparisons reported in the literature but with no clear benefit of one intervention over another. AT, Achilles tendinopathy; Ecc, eccentric training; GTPS, greater trochanteric pain syndrome; HT, home training; MTSS, medial tibial stress syndrome; PHT, proximal hamstring tendinopathy; PRP, platelet-rich plasma; PT, patellar tendinopathy; Running, graded running programme; Suppl, dietary supplements; Wait, wait-and-see policy.

'minimally worse' $\leq-0.08 / 10$; 'no change' $\leq-0.20 / 10$; 'minimally improved' $\leq-1.07 / 10$; 'much improved' $\leq-2.69 / 10$; and 'very much improved' $\leq-4.15 / 10$.

\section{Mid-portion AT}

Studies assessing the effectiveness of ESWT in AT were subgrouped into three categories according to the diagnosis patients received during inclusion in each study: mid-portion tendinopathy, insertional tendinopathy or mixed/non-specified. ${ }^{63}$

Included and excluded studies

Four studies ${ }^{5-79}$ assessed the effectiveness of ESWT in mid-portion AT (see online supplementary table 2). One fair quality prospective study ${ }^{9}$ reporting favourable pain and functional outcomes with ESWT was excluded due to non-controlled design. One non-randomised controlled study ${ }^{5}$ of good quality comparing focused ESWT with traditional non-operative therapy did not meet the inclusion criteria. We excluded this study because of the use of regional block with or without sedation (as this does not reflect standard clinical practice) and possible selection bias in the control group (financial or insurance coverage). This study compared ESWT with traditional non-operative therapy up to 12-month follow-up. Scores in VISA-A, perceived recovery and pain reduction favoured participants in the ESWT group at all follow-up assessments.

Two RCTs ${ }^{67}$ with low risk of bias-one ${ }^{7}$ of excellent and one ${ }^{6}$ of good quality assessing the effectiveness of radial ESWT (used same protocol) - met the inclusion criteria for quantitative synthesis. Both studies performed analyses according to the intention-totreat principle. The duration of follow-up for both was 4 months, the mean age of the participants ranged from 46.2 to 53.1 years and the mean duration of symptoms varied from 9.2 months to 16 months (online supplementary table 2). The definition of mid-portion AT was pain over the main body of Achilles tendon 2-6 cm proximal to its insertion, swelling and impaired function. Both studies included patients with a history of AT for at least 6 months and failure of non-operative management. ${ }^{67}$ A total number of 143 patients were randomised into ESWT, ESWT additive to eccentric loading, eccentric loading or wait-and-see policy groups.

\section{Effects of interventions}

Effects of interventions regarding functional disability, pain reduction, self-perceived recovery and patient-rated pain reduction are presented in table 2. Comparison parameters, forest plots and criteria for quantitative synthesis are presented in detail in online supplementary appendix 4. 

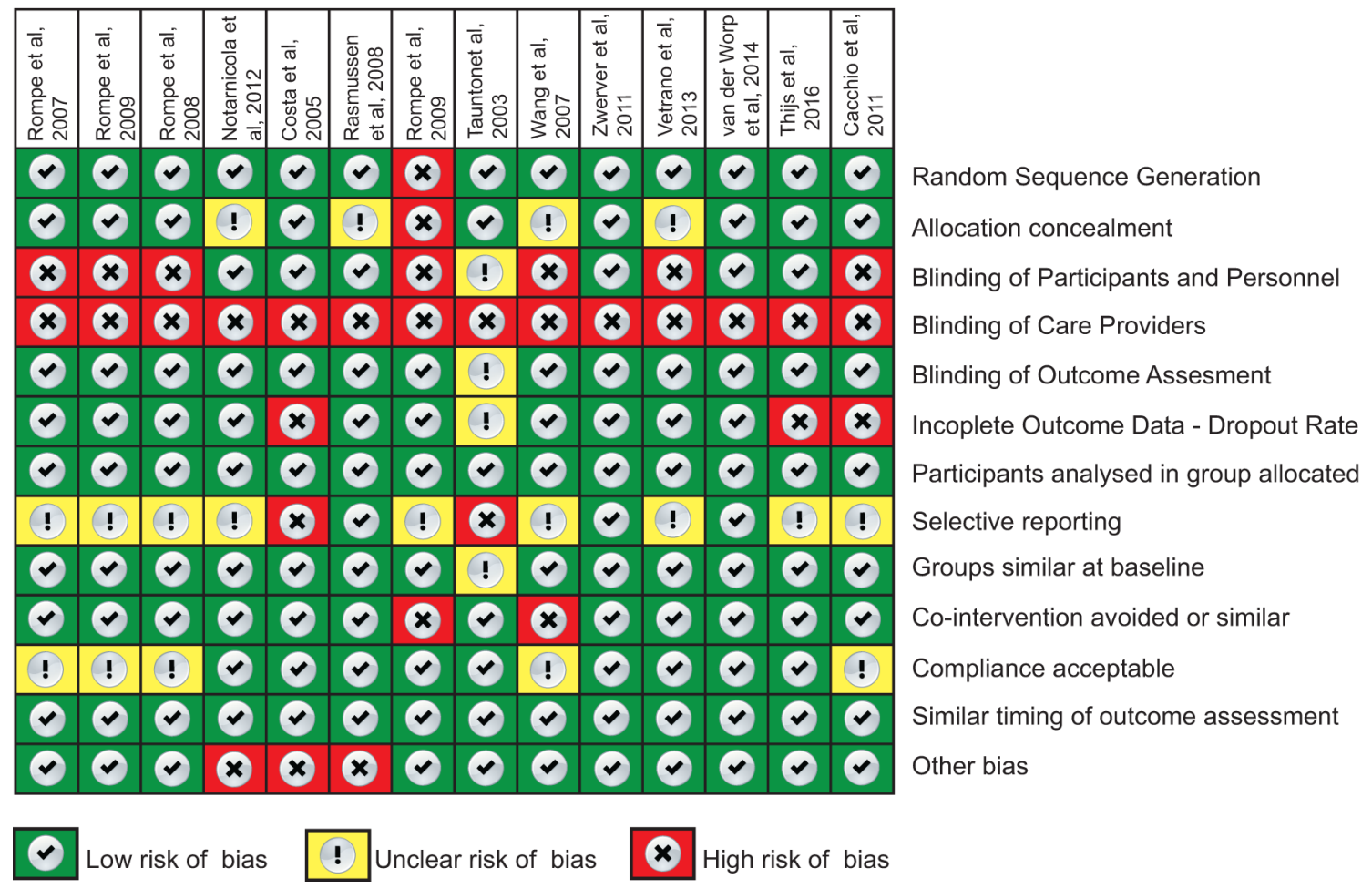

Low risk of bias

! Unclear risk of bias

( High risk of bias

Figure 3 Summary of risk of bias for $15^{1467141517202225-2729-31}$ eligible studies for bias assessment. Note that eight studies ${ }^{8-132324}$ without a comparator intervention were not assessed with the risk of bias tool, as well as eight case-control studies. ${ }^{2351618192128}$

Conclusion and recommendations

Low level of evidence:

1. Radial ESWT is comparable to eccentric training at mid-term follow-up (4 months) for VISA-A, pain scores, self-perceived recovery and patient rating of pain reduction (both much improved).

2. Radial ESWT is superior to a wait-and-see policy at midterm follow-up (4 months) for disability scores, pain, selfperceived recovery and patient rating of pain reduction (much improved compared with minimally improved).

Very low level of evidence:

1. Radial ESWT combined with eccentric training is superior to eccentric training alone at mid-term follow-up (4 months) for VISA-A scores, self-perceived recovery and patient-rated pain reduction (very much improved compared with much improved).

Suggested protocol:

By using radial ESWT, deliver 2000 impulses at three bars (energy flux density $0.1 \mathrm{~mJ} / \mathrm{mm}^{2}$ ) at $8 \mathrm{~Hz}$ for three sessions at weekly intervals.

\section{Insertional AT}

Included and excluded studies

Four studies ${ }^{1-4}$ evaluated focused or radial ESWT in patients with insertional AT. Two non-randomised controlled studies $^{2} 3$ (see online supplementary table 2) were excluded: one ${ }^{2}$ assessing focused ESWT compared with surgery due to poor quality, and the other ${ }^{3}$ evaluating effectiveness of focused ESWT compared with orthoses, non-steroidal anti-inflammatory drugs (NSAID), massage, physiotherapy, stretching, strengthening, ultrasound, ice, iontophoresis, contrast baths and immobilisation because of fair quality, selection bias of the control group (insurance coverage) and the possibility of author's conflict of interest. Finally, we excluded an RCT $^{1}$ with low risk of bias due to indirectness of comparison (three domains of intervention; ESWT, eccentric loading and dietary supplements).

Only one $\mathrm{RCT}^{4}$ with low risk of bias, assessing the effectiveness of radial ESWT compared with eccentric loading in a total of 50 patients, met the inclusion criteria. The study was performed on an intention-to-treat basis. The duration of follow-up was 4 months, the mean age of the participants ranged from 39.2 to 40.4 years and the mean duration of symptoms varied from 24.8 months to 26.3 months (see online supplementary table 2). The definition of insertional AT was localised pain over the distal part of Achilles tendon at its insertion onto the calcaneus, with local tenderness, and reduced levels of activity. The study included patients with a history of AT for at least 6 months and failure of non-operative management. ${ }^{4}$

\section{Effects of interventions}

Effects of interventions regarding functional disability, pain reduction, self-perceived recovery and patient-rated pain reduction are presented in table 3. Comparison parameters, forest plots and criteria for quantitative synthesis are presented in detail in online supplementary appendix 4.

\section{Conclusion and recommendations}

Low level of evidence:

1. Radial ESWT is superior to eccentric training at mid-term follow-up (4 months) for disability scores, pain, self-perceived recovery and patient rating of pain reduction (much improved compared with minimally improved).

Suggested protocol:

By using radial ESWT deliver 2000 impulses at 2.5 bars (energy flux density $0.12 \mathrm{~mJ} / \mathrm{mm}^{2}$ ) at $8 \mathrm{~Hz}$ for three sessions at weekly intervals. 


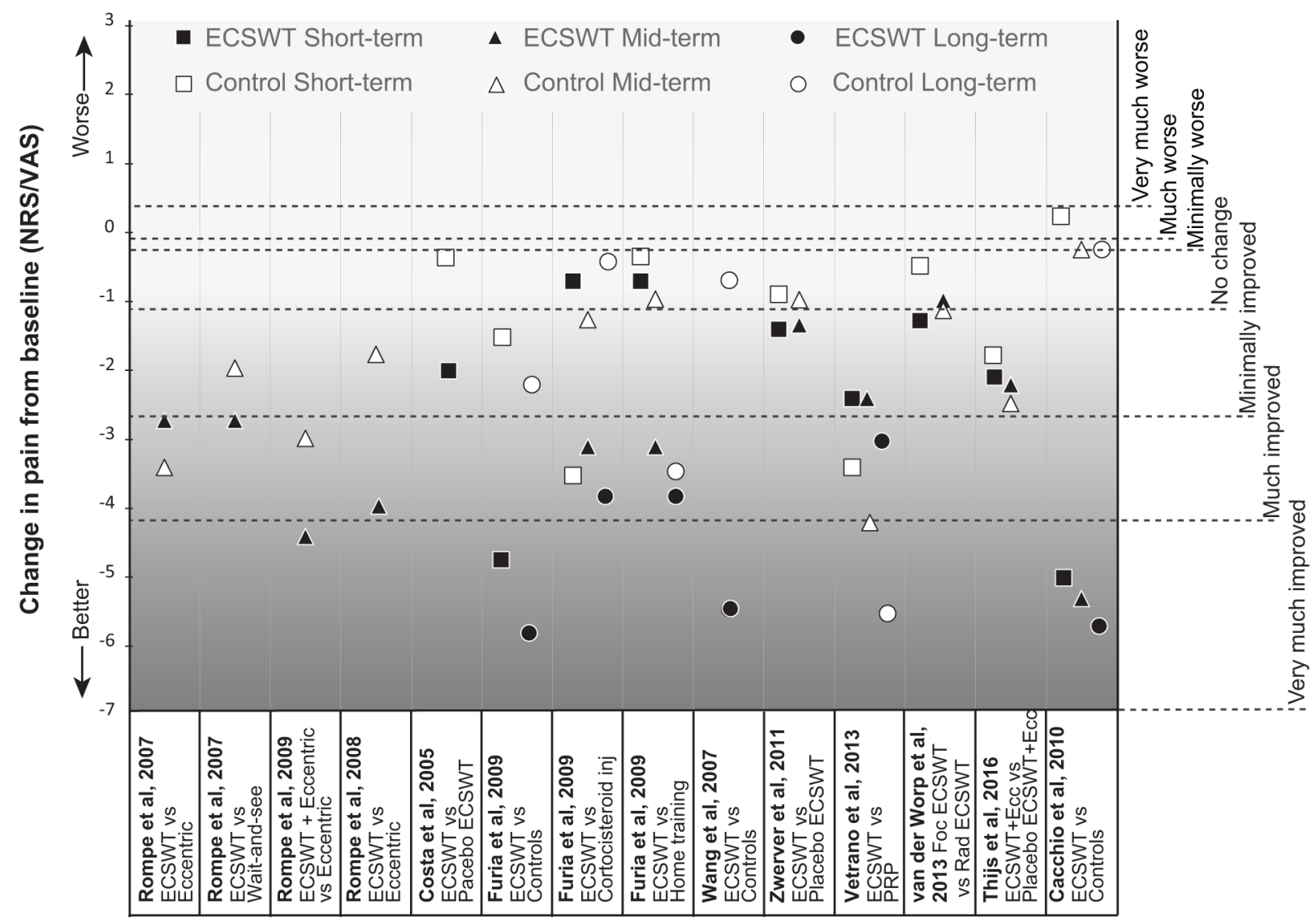

Figure 4 Graphical representation of clinically meaningful patient-rated change in pain for extracorporeal shockwave therapy (ESWT) (black shapes) and control groups (white shapes) at different time points of follow-up. Time points are categorised as short term: $\leq 3$ months; mid-term: 3-12 months; long term: $\geq 12$ months. Change in pain is represented on the left vertical axis with negative values indicating an improvement in pain, that is, a reduction in visual analogue scale (VAS)/numeric rating scale (NRS). The right vertical axis depicts the patient-reported descriptors associated with these changes in pain.

\section{Mixed/non-specified AT}

Included and excluded studies

Five prospective non-controlled studies ${ }^{8}{ }^{10-13}$ of fair and poor quality (online supplementary table 2) were excluded from quantitative synthesis. Most non-controlled studies reported significant improvement at pain and/or functional scores at the long-term follow-up ( $\geq 12$ months). ${ }^{8}{ }^{10-12}$ Only one study ${ }^{13}$ reported pain reduction in favour of ESWT at 12 month follow-up, better results in non-insertional AT compared with insertional, but no significant improvement at 2-year follow-up.

Two RCTs ${ }^{1415}$ with low risk of bias assessing the effectiveness of ESWT in mixed/non-specified groups of patients with AT were included for quantitative synthesis. Both studies used as an inclusion criterion tenderness exacerbated by dorsiflexion of the ankle, but the definition of AT was broad in both reflecting the mixed group of patients included. Both studies performed analyses according to the intention-to-treat principle. The studies enrolled 97 patients, their mean age ranged from 46 to 58.7 years; the follow-up assessment was performed in both at 3 months, but the mean duration of symptoms is reported only in one study ${ }^{14}$ (varied from 17.8 to 20.8 months). Costa et $a l^{14}$ compared ESWT with placebo shock wave, while Rasmussen $e a^{15}$ used ESWT or placebo additive to stretching and eccentric training.

\section{Effects of interventions}

Effects of interventions regarding functional disability, pain reduction, self-perceived recovery and patient-rated pain reduction are presented in table 4. Comparison parameters, forest plots and criteria for quantitative synthesis are presented in detail in online supplementary appendix 4.

\section{Conclusion and recommendations}

Very low level of evidence:

1. Both radial and focused ESWT are superior to placebo ESWT at short-term follow-up (3 months) for disability scores, but in non-condition-specific outcome measures.

2. No difference between focused and placebo ESWT in pain reduction, and activities of daily living.

Suggested protocol:

Not applicable due to substantial heterogeneity in studies' protocols.

\section{Greater trochanteric pain syndrome}

Included and excluded studies

One $\mathrm{RCT}^{17}$ with low risk of bias and a good quality non-randomised controlled study ${ }^{16}$ that met all the predefined criteria were included in quantitative synthesis. Both studies included four comparison groups with a total number of 295 patients with GTPS, of which 111 received radial ESWT, 75 corticosteroid injections, 75 home training programme consisted of strengthening and stretching, and 33 traditional non-operative treatment (ie, stretching and strengthening, physical therapy modalities, iontophoresis, rest). The duration of follow-up for both was $\geq 12$ months, the mean age of the participants ranged 
Table 2 Mid-portion Achilles tendinopathy summary of evidence

\begin{tabular}{|c|c|c|c|c|c|c|}
\hline \multirow[b]{2}{*}{ Outcomes } & \multicolumn{2}{|c|}{ Comparisons } & \multirow[b]{2}{*}{ Relative effect $(95 \% \mathrm{CI})$} & \multirow[b]{2}{*}{$\begin{array}{l}\text { Patients / } \\
\text { studies (n) }\end{array}$} & \multirow[b]{2}{*}{$\begin{array}{l}\text { Quality of } \\
\text { evidence } \\
\text { (GRADE) }\end{array}$} & \multirow[b]{2}{*}{ Clinical significance } \\
\hline & $\begin{array}{l}\text { Average estimate / } \\
\text { assumed risk in } \\
\text { the ESWT group }\end{array}$ & $\begin{array}{l}\text { Average estimate/assumed } \\
\text { risk in the control group }\end{array}$ & & & & \\
\hline \multirow[t]{3}{*}{$\begin{array}{l}\text { VISA-A score } \\
\text { Follow-up: } 4 \text { months }\end{array}$} & $\begin{array}{l}\text { ESWT: mean } \pm \text { SD was } \\
70.4 \pm 16.3\end{array}$ & $\begin{array}{l}\text { Eccentric load: mean } \pm \text { SD was } \\
75.6 \pm 18.7\end{array}$ & $\begin{array}{l}\text { MD }-5.2 \\
\text { (14.92 to } 4.52) \\
\text { The difference was not } \\
\text { statistically significant }\end{array}$ & $50 / 1$ & $\begin{array}{l}\oplus \bigoplus^{1} \\
\text { Low }^{1}\end{array}$ & $\begin{array}{l}\text { Low level of evidence showed no } \\
\text { difference between radial ESWT } \\
\text { and eccentric training in VISA-A } \\
\text { score }\end{array}$ \\
\hline & $\begin{array}{l}\text { ESWT: mean } \pm S D \text { was } \\
70.4 \pm 16.3\end{array}$ & $\begin{array}{l}\text { Wait-and-see: mean } \pm \text { SD was } \\
55.0 \pm 12.9\end{array}$ & $\begin{array}{l}\text { MD } 15.40 \\
\text { (7.25 to } 23.55) \\
\text { The difference was } \\
\text { statistically and clinically } \\
\text { significant }\end{array}$ & $50 / 1$ & $\begin{array}{l}\oplus \oplus \\
\text { Low }^{1}\end{array}$ & $\begin{array}{l}\text { Low level of evidence in favour } \\
\text { of radial ESWT compared with } \\
\text { wait-and-see policy in VISA-A } \\
\text { score }\end{array}$ \\
\hline & $\begin{array}{l}\text { ESWT + eccentric } \\
\text { load: mean } \pm \text { SD was } \\
86.5 \pm 16.0\end{array}$ & $\begin{array}{l}\text { Eccentric load: mean } \pm S D \text { was } \\
73.0 \pm 19.0\end{array}$ & $\begin{array}{l}\text { MD } 13.50 \\
\text { (5.15 to } 21.85) \\
\text { The difference was } \\
\text { statistically and clinically } \\
\text { significant }\end{array}$ & $68 / 1$ & $\begin{array}{l}\bigoplus \\
\text { Very low }\end{array}$ & $\begin{array}{l}\text { Very low level of evidence in } \\
\text { favour of radial ESWT additive } \\
\text { to eccentric training compared } \\
\text { with eccentric training alone in } \\
\text { VISA-A score }\end{array}$ \\
\hline \multirow{3}{*}{$\begin{array}{l}\text { Self-perceived recovery } \\
\text { Defined as completely } \\
\text { recovered and much } \\
\text { improved } \\
\text { Follow-up: } 4 \text { months }\end{array}$} & $\begin{array}{l}\text { ESWT: } 13 \text { of } 25(52 \%) \\
\text { participants reported } \\
\text { satisfactory recovery }\end{array}$ & $\begin{array}{l}\text { Eccentric load: } 15 \text { of } 25 \\
(60 \%) \text { participants reported } \\
\text { satisfactory recovery }\end{array}$ & $\begin{array}{l}\text { OR } 0.72,(0.24 \text { to } 2.21) \\
\text { The difference was not } \\
\text { statistically significant }\end{array}$ & $50 / 1$ & $\begin{array}{l}\bigoplus \oplus \\
\text { Low }^{1}\end{array}$ & $\begin{array}{l}\text { Low level of evidence showed no } \\
\text { difference between radial ESWT } \\
\text { and eccentric training in patient- } \\
\text { rated recovery }\end{array}$ \\
\hline & $\begin{array}{l}\text { ESWT: } 13 \text { of } 25(52 \%) \\
\text { participants reported } \\
\text { satisfactory recovery }\end{array}$ & $\begin{array}{l}\text { Wait-and-see: } 6 \text { of } 25 \\
(24 \%) \text { participants reported } \\
\text { satisfactory recovery }\end{array}$ & $\begin{array}{l}\text { OR } 3.43 \\
(1.03 \text { to } 11.48) \\
\text { The difference was } \\
\text { statistically significant }\end{array}$ & $50 / 1$ & $\begin{array}{l}\oplus \bigoplus \\
\text { Low }^{1}\end{array}$ & $\begin{array}{l}\text { Low level of evidence in favour } \\
\text { of radial ESWT compared with } \\
\text { wait-and-see policy in patient- } \\
\text { rated recovery }\end{array}$ \\
\hline & $\begin{array}{l}\text { ESWT + eccentric } \\
\text { load: } 28 \text { of } 34(82 \%) \\
\text { participants reported } \\
\text { satisfactory recovery }\end{array}$ & $\begin{array}{l}\text { Eccentric load: } 9 \text { of } 34 \\
(26 \%) \text { participants reported } \\
\text { satisfactory recovery }\end{array}$ & $\begin{array}{l}\text { OR } 12.96 \\
\text { (4.04 to } 41.57) \\
\text { The difference was } \\
\text { statistically significant }\end{array}$ & $68 / 1$ & $\begin{array}{l}\bigoplus \\
\text { Very low }\end{array}$ & $\begin{array}{l}\text { Very low level of evidence in } \\
\text { favour of radial ESWT additive } \\
\text { to eccentric training compared } \\
\text { with eccentric training alone in } \\
\text { patient-rated recovery }\end{array}$ \\
\hline \multirow[t]{3}{*}{$\begin{array}{l}\text { NRS pain score* } \\
\text { Follow-up: } 4 \text { months }\end{array}$} & $\begin{array}{l}\text { ESWT: mean } \pm \text { SD was } \\
4.0 \pm 2.2\end{array}$ & $\begin{array}{l}\text { Eccentric load: mean } \pm \text { SD was } \\
3.6 \pm 2.3\end{array}$ & $\begin{array}{l}\text { MD } 0.40 \\
\text { (-0.85 to } 1.65) \\
\text { The difference was not } \\
\text { statistically significant }\end{array}$ & $50 / 1$ & $\begin{array}{l}\oplus \bigoplus^{1} \\
\text { Low }^{1}\end{array}$ & $\begin{array}{l}\text { Low level of evidence showed no } \\
\text { difference in pain between radial } \\
\text { ESWT and eccentric training in } \\
\text { NRS score }\end{array}$ \\
\hline & $\begin{array}{l}\text { ESWT: mean } \pm S D \text { was } \\
4.0 \pm 2.2\end{array}$ & $\begin{array}{l}\text { Wait-and-see: mean } \pm \text { SD was } \\
5.9 \pm 1.8\end{array}$ & $\begin{array}{l}\text { MD }-1.90 \\
(-3.01 \text { to to } 0.79) \\
\text { The difference was } \\
\text { statistically but not clinically } \\
\text { significant }\end{array}$ & $50 / 1$ & $\begin{array}{l}\oplus \bigoplus \\
\text { Low }^{1}\end{array}$ & $\begin{array}{l}\text { Low level of evidence in favour } \\
\text { of radial ESWT compared with } \\
\text { wait-and-see policy in NRS pain } \\
\text { reduction, but not clinically } \\
\text { significant }\end{array}$ \\
\hline & $\begin{array}{l}\text { ESWT + eccentric load: } \\
\text { mean } \pm \text { SD was } 2.4 \pm 2.2\end{array}$ & $\begin{array}{l}\text { Eccentric load: mean } \pm \text { SD was } \\
3.9 \pm 2.0\end{array}$ & $\begin{array}{l}\text { MD }-1.50 \\
(-2.50 \text { to to } 0.50) \\
\text { The difference was } \\
\text { statistically, but not clinically } \\
\text { significant }\end{array}$ & $68 / 1$ & $\begin{array}{l}\oplus \\
\text { Very low }\end{array}$ & $\begin{array}{l}\text { Very low level of evidence in } \\
\text { favour of radial ESWT additive } \\
\text { to eccentric training compared } \\
\text { with eccentric training alone } \\
\text { in NRS score, but not clinically } \\
\text { significant }\end{array}$ \\
\hline \multirow{3}{*}{$\begin{array}{l}\text { Patient-rated pain } \\
\text { reduction** } \\
\text { Cut-off points adjusted } \\
\text { from Farrar et al }{ }^{44} \\
\text { Follow-up: } 4 \text { months }\end{array}$} & $\begin{array}{l}\text { ESWT: MD from } \\
\text { baseline was } 2.8 \text { points }\end{array}$ & $\begin{array}{l}\text { Eccentric load: MD from } \\
\text { baseline was } 3.4 \text { points }\end{array}$ & Not estimable & $50 / 1$ & $\mathrm{~N} / \mathrm{A}$ & $\begin{array}{l}\text { ESWT: much improved } \\
\text { Eccentric load: much improved }\end{array}$ \\
\hline & $\begin{array}{l}\text { ESWT: MD from } \\
\text { baseline was } 2.8 \text { points }\end{array}$ & $\begin{array}{l}\text { Wait-and-see: MD from } \\
\text { baseline was } 2.0 \text { points }\end{array}$ & Not estimable & $50 / 1$ & $N / A$ & $\begin{array}{l}\text { ESWT: much improved } \\
\text { Wait-and-see: minimally } \\
\text { improved }\end{array}$ \\
\hline & $\begin{array}{l}\text { ESWT + eccentric load: } \\
\text { MD from baseline was } \\
4.4 \text { points }\end{array}$ & $\begin{array}{l}\text { Eccentric load: MD from } \\
\text { baseline was } 3.1 \text { points }\end{array}$ & Not estimable & $68 / 1$ & $\mathrm{~N} / \mathrm{A}$ & $\begin{array}{l}\text { ESWT + eccentric load: very } \\
\text { much improved } \\
\text { Eccentric load: much improved }\end{array}$ \\
\hline
\end{tabular}

${ }^{*}$ Load-induced pain.

${ }^{* *}$ Cut-off points adjusted from Farrar et al ${ }^{44}$

${ }^{1}$ Only one high-quality randomised controlled trial was available for analysis.

${ }^{2}$ Indirect comparison.

ESWT, extracorporeal shockwave therapy; GRADE, Grading of Recommendations Assessment, Development and Evaluation; MD, mean difference; N/A, not available;

NRS, numeric rating scale.

from 46 to 51 years and the mean duration of symptoms varied from 11 to 14 months (see online supplementary table 2). In general, definition of GTPS was pain located over and around the greater trochanter area with or without tenderness. Rompe et $a l^{17}$ in the definition also included positive resisted external hip rotation test, pain while lying on the affected side, and no radiological evidence at hip imaging. Conversely, Furia et $a l^{16}$ included in the definition pain with resisted hip abduction and impaired function, but for confirmation of diagnosis they used local anaesthetic injection. 
Table 3 Insertional Achilles tendinopathy summary of evidence

\begin{tabular}{|c|c|c|c|c|c|c|}
\hline \multirow[b]{2}{*}{ Outcomes } & \multicolumn{2}{|c|}{ Comparisons } & \multirow[b]{2}{*}{ Relative effect $(95 \% \mathrm{CI})$} & \multirow[b]{2}{*}{$\begin{array}{l}\text { Patients / } \\
\text { studies (n) }\end{array}$} & \multirow[b]{2}{*}{$\begin{array}{l}\text { Quality of } \\
\text { evidence } \\
\text { (GRADE) }\end{array}$} & \multirow[b]{2}{*}{ Clinical significance } \\
\hline & $\begin{array}{l}\text { Average estimate/ } \\
\text { assumed risk in } \\
\text { the ESWT group }\end{array}$ & $\begin{array}{l}\text { Average estimate/ } \\
\text { assumed risk in } \\
\text { the control group }\end{array}$ & & & & \\
\hline $\begin{array}{l}\text { VISA-A score } \\
\text { Follow-up: } 4 \text { months }\end{array}$ & $\begin{array}{l}\text { ESWT: mean } \pm \text { SD was } \\
79.4 \pm 10.4\end{array}$ & $\begin{array}{l}\text { Eccentric load: } \\
\text { mean } \pm \text { SD was } \\
63.4 \pm 12.0\end{array}$ & $\begin{array}{l}\text { MD } 16.00 \\
(9.78 \text { to } 22.22) \\
\text { The difference was clinically and } \\
\text { statistically significant }\end{array}$ & $50 / 1$ & $\begin{array}{l}\oplus \bigoplus^{1} \\
\text { Low }^{1}\end{array}$ & $\begin{array}{l}\text { Low level of evidence in favour } \\
\text { of radial ESWT compared with } \\
\text { eccentric training in VISA-A score }\end{array}$ \\
\hline $\begin{array}{l}\text { Self-perceived recovery } \\
\text { Defined as completely } \\
\text { recovered and much } \\
\text { improved } \\
\text { Follow-up: } 4 \text { months }\end{array}$ & $\begin{array}{l}\text { ESWT: } 16 \text { of } 25 \\
(66 \%) \text { participants } \\
\text { reported satisfactory } \\
\text { recovery }\end{array}$ & $\begin{array}{l}\text { Eccentric load: } 7 \text { of } \\
25(28 \%) \text { participants } \\
\text { reported satisfactory } \\
\text { recovery }\end{array}$ & $\begin{array}{l}\text { OR } 4.57,(1.38 \text { to } 15.11) \\
\text { The difference was statistically } \\
\text { significant }\end{array}$ & $50 / 1$ & $\begin{array}{l}\bigoplus \bigoplus \\
\text { Low }^{1}\end{array}$ & $\begin{array}{l}\text { Low level of evidence in favour } \\
\text { of radial ESWT compared } \\
\text { with eccentric training in patient- } \\
\text { rated recovery }\end{array}$ \\
\hline $\begin{array}{l}\text { NRS pain score* } \\
\text { Follow-up: } 4 \text { months }\end{array}$ & $\begin{array}{l}\text { ESWT: mean } \pm S D \text { was } \\
3.0 \pm 2.3\end{array}$ & $\begin{array}{l}\text { Eccentric load: } \\
\text { mean } \pm S D \text { was } 5.0 \pm 2.3\end{array}$ & $\begin{array}{l}\text { MD }-2.00 \\
(-3.28 \text { to } 0.72) \\
\text { The difference was clinically and } \\
\text { statistically significant }\end{array}$ & $50 / 1$ & $\begin{array}{l}\oplus \bigoplus^{1} \\
\text { Low }^{1}\end{array}$ & $\begin{array}{l}\text { Low level of evidence in favour } \\
\text { of radial ESWT compared with } \\
\text { eccentric training in NRS pain } \\
\text { reduction scores }\end{array}$ \\
\hline $\begin{array}{l}\text { Patient-rated pain } \\
\text { reduction** } \\
\text { Follow-up: } \\
4 \text { months }\end{array}$ & $\begin{array}{l}\text { ESWT: MD from } \\
\text { baseline was } 4.0 \\
\text { points }\end{array}$ & $\begin{array}{l}\text { Eccentric load: MD from } \\
\text { baseline was } 1.8 \text { points }\end{array}$ & Not estimable & $50 / 1$ & N/A & $\begin{array}{l}\text { ESWT: much improved } \\
\text { Eccentric load: minimally improved }\end{array}$ \\
\hline
\end{tabular}

* Load-induced pain.

${ }^{* *}$ Cut-off points adjusted from Farrar et al. ${ }^{44}$

${ }^{1}$ Only one high-quality randomised controlled trial was available for analysis.

ESWT, extracorporeal shockwave therapy; GRADE, Grading of Recommendations Assessment, Development and Evaluation; MD, mean difference; N/A, not available;

NRS, numeric rating scale.

\section{Effects of interventions}

Effects of interventions regarding functional disability, pain reduction, self-perceived recovery and patient-rated pain reduction are presented in table 5. Comparison parameters, forest plots and criteria for quantitative synthesis are presented in detail in online supplementary appendix 4 .
Conclusion and recommendations

Very low level of evidence:

1. Radial ESWT is superior to control treatment (physiotherapy, stretching and strengthening) at short (3 months) and longterm follow-up (12 months) for disability scores (HHS).

Low level of evidence:

Table 4 Mixed/non-specified Achilles tendinopathy summary of evidence

\begin{tabular}{|c|c|c|c|c|c|c|}
\hline \multirow[b]{2}{*}{ Outcomes } & \multicolumn{2}{|c|}{ Comparisons } & \multirow[b]{2}{*}{ Relative effect $(95 \% \mathrm{Cl})$} & \multirow[b]{2}{*}{$\begin{array}{l}\text { Patients / } \\
\text { studies (n) }\end{array}$} & \multirow[b]{2}{*}{$\begin{array}{l}\text { Quality of } \\
\text { evidence } \\
\text { (GRADE) }\end{array}$} & \multirow[b]{2}{*}{ Clinical significance } \\
\hline & $\begin{array}{l}\text { Average estimate / } \\
\text { assumed risk in } \\
\text { the ESWT group }\end{array}$ & $\begin{array}{l}\text { Average estimate /assumed } \\
\text { risk in the control group }\end{array}$ & & & & \\
\hline $\begin{array}{l}\text { FIL and AOFAS scores } \\
\text { Follow-up: } 3 \text { months }\end{array}$ & $\begin{array}{l}\text { ESWT: The mean } \\
\text { standardised disability } \\
\text { score was } 91.5 \text { (range } \\
88.0-95.0 \text { ) }\end{array}$ & $\begin{array}{l}\text { Placebo ESWT: the mean } \\
\text { standardised disability score } \\
\text { was } 52.2 \text { (range } 24.0-81.0 \text { ) }\end{array}$ & $\begin{array}{l}\text { SMD* } 0.77 \\
(0.25 \text { to } 1.30) \\
\text { The difference was clinically and } \\
\text { statistically significant }\end{array}$ & $97 / 2$ & $\begin{array}{l}\oplus \\
\text { Very low }\end{array}$ & $\begin{array}{l}\text { Very low level of evidence } \\
\text { in favour of ESWT } \\
\text { compared with placebo } \\
\text { ESWT in non-condition } \\
\text { specific functional outcome } \\
\text { measures }\end{array}$ \\
\hline $\begin{array}{l}\text { Self-perceived recovery } \\
\text { Defined by EQ-5D } \\
\text { Follow-up: } 3 \text { months }\end{array}$ & $\begin{array}{l}\text { ESWT: mean } \pm S D \text { was } \\
0.11 \pm 0.24\end{array}$ & $\begin{array}{l}\text { Placebo ESWT: mean } \pm \text { SD was } \\
0.07 \pm 0.24\end{array}$ & $\begin{array}{l}\text { MD } 0.04 \\
(-0.10 \text { to } 0.18) \\
\text { The difference was not } \\
\text { statistically significant }\end{array}$ & $49 / 1$ & $\begin{array}{l}\oplus \\
\text { Very low }\end{array}$ & $\begin{array}{l}\text { Very low level of evidence } \\
\text { of no difference between } \\
\text { focused ESWT compared } \\
\text { with placebo ESWT in } \\
\text { activities of daily living }\end{array}$ \\
\hline $\begin{array}{l}\text { VAS pain score* } \\
\text { Follow-up: } 3 \text { months }\end{array}$ & $\begin{array}{l}\text { ESWT: mean } \pm \text { SD was } \\
4.78 \pm 3.14\end{array}$ & $\begin{array}{l}\text { Placebo ESWT: mean } \pm \text { SD was } \\
5.80 \pm 3.8\end{array}$ & $\begin{array}{l}\text { MD }-1.02 \\
(-2.96 \text { to } 0.92) \\
\text { The difference was not } \\
\text { statistically significant }\end{array}$ & $49 / 1$ & $\begin{array}{l}\oplus \\
\text { Very low }\end{array}$ & $\begin{array}{l}\text { Very low level of evidence } \\
\text { of no difference between } \\
\text { focused ESWT compared } \\
\text { with placebo ESWT in VAS } \\
\text { scores }\end{array}$ \\
\hline $\begin{array}{l}\text { Patient-rated pain } \\
\text { reduction*, ** } \\
3 \text { months }\end{array}$ & $\begin{array}{l}\text { ESWT: MD from baseline } \\
\text { was } 2.0 \text { points }\end{array}$ & $\begin{array}{l}\text { Eccentric load: MD from } \\
\text { baseline was } 0.4 \text { points }\end{array}$ & Not estimable & $49 / 1$ & $\mathrm{~N} / \mathrm{A}$ & $\begin{array}{l}\text { ESWT: much improved } \\
\text { Placebo ESWT: minimally } \\
\text { improved }\end{array}$ \\
\hline
\end{tabular}




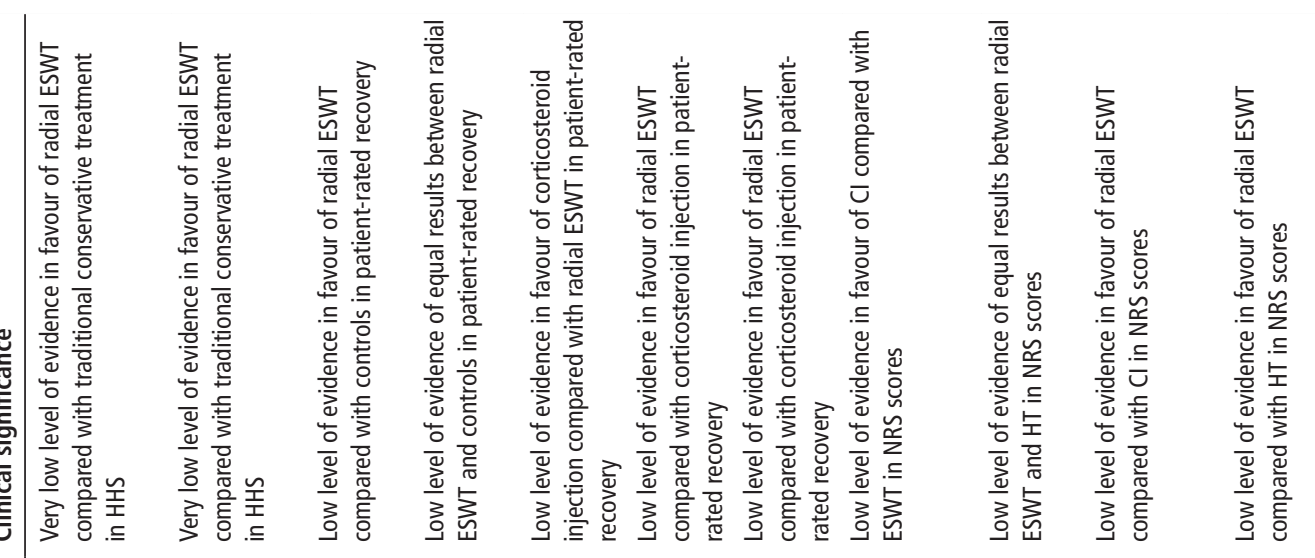

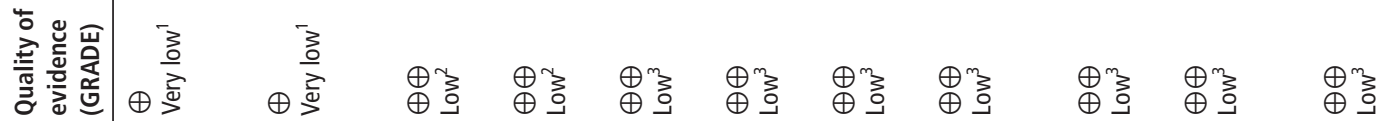
辛

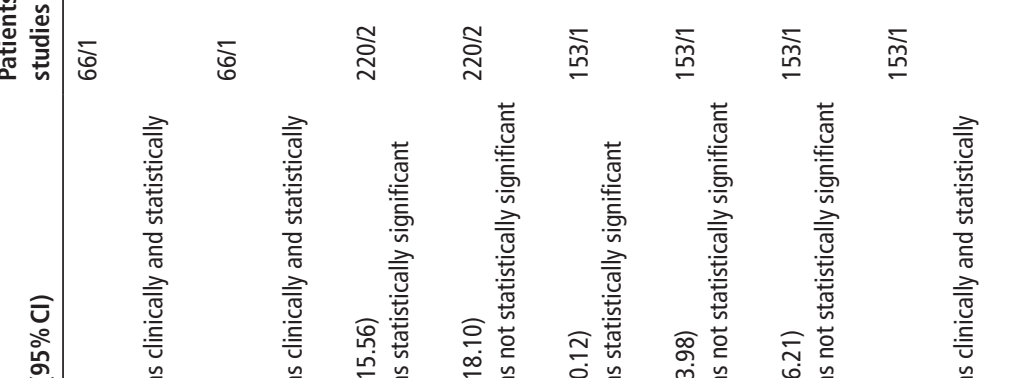

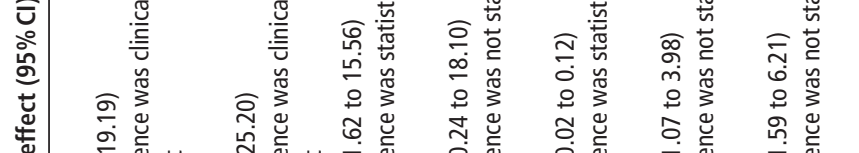

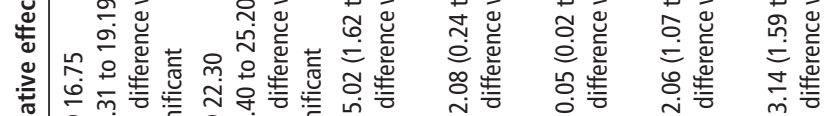

m \&

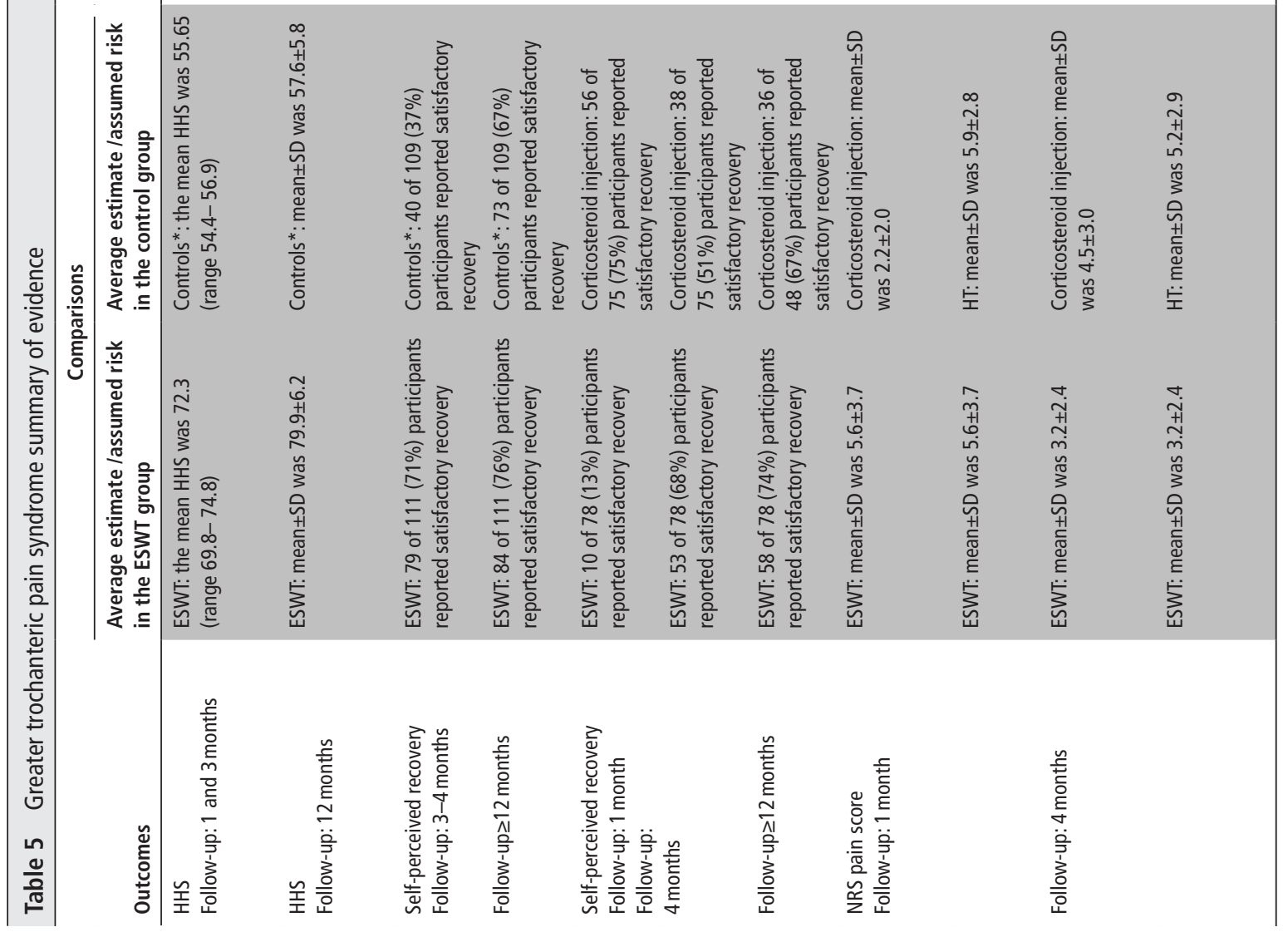




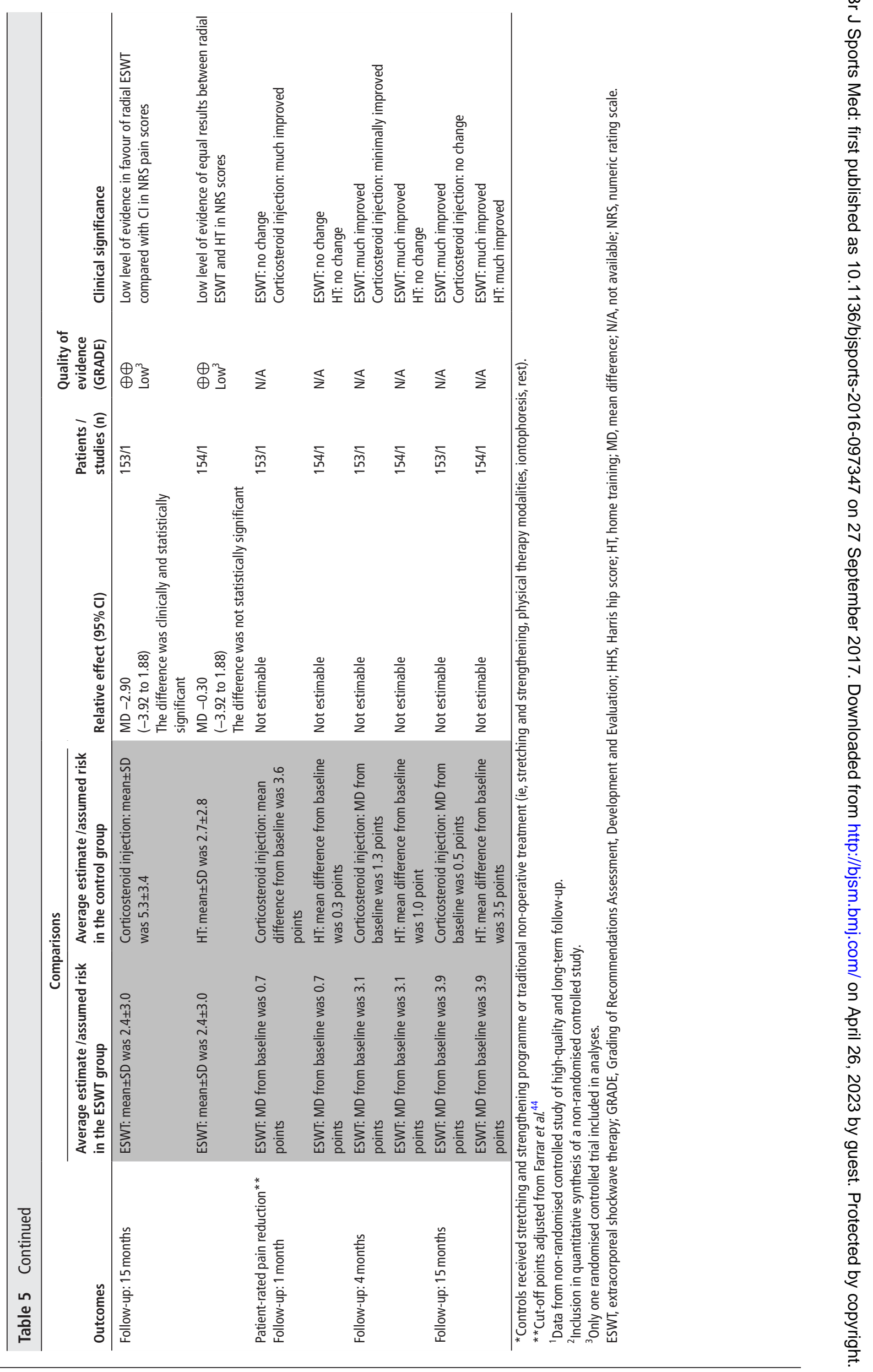


1. Radial ESWT is superior to control treatment (physiotherapy, stretching and strengthening) at short (1-3 months) and midterm follow-up (4 months) in self-perceived recovery.

2. Corticosteroid injection is superior to radial ESWT at shortterm (1 month) follow-up in self-perceived recovery, pain scores and patient-rated pain reduction.

3. Radial ESWT is superior to corticosteroid injection at mid-term (4 months) and long-term follow-up (>12 months) in self-perceived recovery, pain scores and patient-rated pain reduction.

4. Radial ESWT produces comparable results to control treatment (physiotherapy, stretching and strengthening) at long-term follow-up (>12 months) in self-perceived recovery, pain scores and patient-rated pain reduction.

Suggested protocol:

Not applicable due to substantial heterogeneity in studies' protocols.

\section{Medial tibial stress syndrome \\ Included and excluded studies}

Small sample size in one RCT, ${ }^{20}$ and study design, methodological limitations and reporting of data in two non-randomised studies ${ }^{18} 19$ did not allow for a quantitative comparison. Moen et $a l^{18}$ reported that five sessions of focused ESWT added to a graded running programme reduced significantly the time to full recovery (mean 32 days) compared with the running programme in isolation, as assessed by a treadmill running test. On the contrary, a high-quality, low risk of bias $\mathrm{RCT}^{20}$ that used the same ESWT protocol without additive controlled intervention reported no significant differences at 10-week follow-up between ESWT and sham dose ESWT groups in pain during muscle pressure (patient-rated improvement of 'no change' and 'minimally improved', respectively), pain-limited distance run and self-perception of change. Interestingly, pain during bone pressure was significantly reduced at the control group compared with the ESWT group at 10-week follow-up (patientrated improvement of 'minimally improved' and 'no change', respectively). On the other hand, Rompe et al ${ }^{19}$ reported that radial ESWT additive to a standardised home training programme comprising lower limb active range of motion, stretching and strengthening exercises, provided significant benefit in reducing pain and self-perceived global improvement in patients with MTSS. Estimation of patients' rating showed that adjunct ESWT group and home training group were both 'minimally improved' at 1 month. ${ }^{44}$ Regarding 4 and 15 months follow-up, the reduction of pain was seen to be 4.3 and 5.4 points for the ESWT group compared with 1.6 and 3.2 for the home training group, which were both a patient rating of 'very much improved' compared with 'minimally improved' and 'much improved', respectively. ${ }^{44}$

\section{Conclusion and recommendations}

No evidence for the effectiveness of ESWT in patients with MTSS.

Suggested protocol:

Not applicable.

\section{Patellar tendinopathy}

Included and excluded studies

Eleven studies were evaluated for inclusion in quantitative synthesis (see online supplementary table 2). We pooled data from five RCTs ${ }^{25-27} 2930$ of low risk of bias by grouping studies with relatively similar comparisons in order to draw clinically meaningful conclusions and evidence. Three prospective non-controlled studies ${ }^{1023} 24$ of poor and fair quality presenting positive results from ESWT were excluded from quantitative synthesis. Two fair quality non-randomised controlled studies ${ }^{2128}$ were excluded due to retrospective design. One study ${ }^{28}$ reported favourable results for ESWT compared with conservative treatment at long-term follow-up, and the other ${ }^{21}$ comparable results between ESWT and surgery at $>20$ months follow-up. Moreover, an $\mathrm{RCT}^{22}$ with low risk of bias reporting superior results of ESWT compared with placebo shock wave at short term was excluded due to small sample size.

\section{Focused ESWT compared with placebo shock wave}

\section{Included and excluded studies}

Two multicentre double-blinded RCTs with low risk of bias compared ESWT with placebo shock wave with ${ }^{30}$ or without ${ }^{25}$ additive eccentric training. Both studies included a total number of 114 patients with PT, of which 53 received focused ESWT and 61 placebo ESWT with or without eccentric training. Both studies performed analyses according to the intention-to-treat principle. The duration of follow-up for both was $>5$ months, the mean age of the participants ranged from 24.2 to 30.5 years and the mean duration of symptoms varied from 32 to 99.4 weeks (online supplementary table 2). Definition of PT consisted of localised knee in the patellar tendon related to activity, present for $>2$ months, palpation tenderness at the corresponding painful area and VISA-P score $<80$ at baseline.

\section{Effects of interventions}

Effects of interventions regarding functional disability, pain reduction, self-perceived recovery and patient-rated pain reduction are presented in table 6. Comparison parameters, forest plots and criteria for quantitative synthesis are presented in detail in online supplementary appendix 4 .

\section{Conclusion and recommendations}

Moderate level of evidence:

1. No difference between focused ESWT and placebo ESWT at short (3 months) and mid-term (5-6 months) follow-up in VISA-P, pain scores and patient-rated pain reduction.

Low level of evidence:

1. No difference between focused ESWT and placebo ESWT in self-perceived recovery.

Suggested protocol:

Not applicable.

\section{Focused ESWT compared with conservative management} Included and excluded studies

Only one $\mathrm{RCT}^{26}$ with low risk of bias met the criteria for qualitative analysis. Wang $e a^{26}$ evaluated the effectiveness of focused ESWT compared with conservative treatment consisting of NSAIDs, physiotherapy, exercise programme and the use of knee strap in patients with PT and assessed the functional improvement by using VISA-P questionnaire at 2-3-year follow-up (mean 32.7 months for the ESWT group and 28.6 months for the control group). PT was defined as recurrent pain and tenderness attributable to degenerative changes of the patellar tendon for at least 6 months. The study enrolled 50 patients (54 knees), their mean age ranged from 29.4 to 30.2 years (-online supplementary table 2).

\section{Effects of interventions}

Effects of interventions regarding functional disability, pain reduction, self-perceived recovery and patient-rated pain reduction are presented in table 7. Comparison parameters, forest 
Table 6 ESWT compared with placebo shock wave in patellar tendinopathy summary of evidence

\begin{tabular}{|c|c|c|c|c|c|c|}
\hline \multirow[b]{2}{*}{ Outcomes } & \multicolumn{2}{|c|}{ Comparisons } & \multirow[b]{2}{*}{$\begin{array}{l}\text { Relative effect } \\
(95 \% \mathrm{Cl})\end{array}$} & \multirow[b]{2}{*}{$\begin{array}{l}\text { Patients I } \\
\text { studies (n) }\end{array}$} & \multirow[b]{2}{*}{$\begin{array}{l}\text { Quality of } \\
\text { evidence } \\
\text { (GRADE) }\end{array}$} & \multirow[b]{2}{*}{ Clinical significance } \\
\hline & $\begin{array}{l}\text { Average estimate / } \\
\text { assumed risk in } \\
\text { the ESWT group }\end{array}$ & $\begin{array}{l}\text { Average estimate / } \\
\text { assumed risk in the control } \\
\text { group }\end{array}$ & & & & \\
\hline $\begin{array}{l}\text { Self-perceived recovery } \\
\text { Follow-up: } 3 \text { months }\end{array}$ & $\begin{array}{l}\text { ESWT: } 6 \text { of } 18(33 \%) \\
\text { participants reported } \\
\text { satisfactory recovery }\end{array}$ & $\begin{array}{l}\text { Placebo ESWT: } 11 \text { of } 25 \\
(44 \%) \text { participants reported } \\
\text { satisfactory recovery }\end{array}$ & $\begin{array}{l}\text { OR } 0.64 \text { ( } 0.18 \text { to } 2.24 \text { ) } \\
\text { The difference was not } \\
\text { statistically significant }\end{array}$ & $52 / 1$ & $\begin{array}{l}\oplus \bigoplus_{1,2,3} \\
\operatorname{Low}\end{array}$ & $\begin{array}{l}\text { Low level of evidence of no } \\
\text { difference between ESWT and } \\
\text { placebo ESWT in patient-rated } \\
\text { recovery }\end{array}$ \\
\hline $\begin{array}{l}\text { VAS/NRS pain score* } \\
\text { Follow-up: } 3 \text { months }\end{array}$ & $\begin{array}{l}\text { ESWT: mean pain } \\
\text { score was } 2.7 \text { (range } \\
2.0-3.3 \text { ) }\end{array}$ & $\begin{array}{l}\text { Placebo ESWT: mean pain } \\
\text { score was } 3.4 \text { (range 2.9-3.8) }\end{array}$ & $\begin{array}{l}\text { MD }-0.75 \\
(-1.62 \text { to } 0.11) \\
\text { The difference was not } \\
\text { statistically significant }\end{array}$ & $114 / 2$ & $\begin{array}{l}\oplus \oplus \oplus \\
\text { Moderate }^{1,3}\end{array}$ & $\begin{array}{l}\text { Moderate level of evidence of no } \\
\text { difference between focused ESWT } \\
\text { and placebo ESWT in pain scores }\end{array}$ \\
\hline Follow-up: 5-6 months & $\begin{array}{l}\text { ESWT: mean pain score } \\
\text { was } 2.5 \text { (range 1.8-3.2) }\end{array}$ & $\begin{array}{l}\text { Placebo ESWT: mean pain } \\
\text { score was } 2.9 \text { (range } 2.2-3.6 \text { ) }\end{array}$ & $\begin{array}{l}\text { MD }-0.40 \\
(-1.29 \text { to } 0.49) \\
\text { The difference was not } \\
\text { statistically significant }\end{array}$ & $114 / 2$ & $\begin{array}{l}\oplus \oplus \oplus \\
\text { Moderate }^{1,2}\end{array}$ & $\begin{array}{l}\text { Moderate level of evidence of no } \\
\text { difference between focused ESWT } \\
\text { and placebo ESWT in pain scores }\end{array}$ \\
\hline \multirow{2}{*}{$\begin{array}{l}\text { Patient-rated } \\
\text { pain reduction** } \\
\text { Follow-up: } 3 \text { months } \\
\text { Follow-up: } 5-6 \text { months }\end{array}$} & $\begin{array}{l}\text { ESWT: MD from } \\
\text { baseline ranged from } \\
1.3 \text { to } 2.1 \text { points }\end{array}$ & $\begin{array}{l}\text { Placebo ESWT: MD from } \\
\text { baseline ranged from } 0.8 \text { to } \\
1.8 \text { points }\end{array}$ & Not estimable & $114 / 2$ & $\mathrm{~N} / \mathrm{A}$ & $\begin{array}{l}\text { ESWT: minimal improvement } \\
\text { Placebo ESWT: minimally improved } \\
\text { no change }\end{array}$ \\
\hline & $\begin{array}{l}\text { ESWT: MD from } \\
\text { baseline ranged from } \\
1.4 \text { to } 2.3 \text { points }\end{array}$ & $\begin{array}{l}\text { Placebo ESWT: MD from } \\
\text { baseline ranged from } 1.0 \text { to } \\
2.5 \text { points }\end{array}$ & Not estimable & $114 / 2$ & N/A & $\begin{array}{l}\text { ESWT: minimal improvement } \\
\text { Placebo ESWT: no change/ } \\
\text { minimally improved }\end{array}$ \\
\hline
\end{tabular}

${ }^{*}$ Pain scores are referred to 10 decline squats on injured leg.

${ }^{*}$ Cut-off points adjusted from Farrar et al. ${ }^{44}$

${ }^{1}$ Increased drop-out rate/attrition bias.

${ }^{2}$ Indirect comparison.

${ }^{3}$ Only one randomised controlled trial included in analysis.

ESWT, extracorporeal shockwave therapy; GRADE, Grading of Recommendations Assessment, Development and Evaluation; MD, mean difference; N/A, not available;

NRS, numeric rating scale; VAS, visual analogue scale.

plots and criteria for quantitative synthesis are presented in detail in online supplementary appendix 4.

\section{Conclusion and recommendations}

Low level of evidence:

1. Focused ESWT is superior to control conservative treatment (NSAID, physiotherapy, exercise, knee strap, modification of activity levels) at long-term follow-up (2-3 years) in VISA-P, self-perceived recovery, pain scores and patient-rated pain reduction.

Suggested protocol:

Not applicable due to substantial heterogeneity in PT studies' protocols.

\section{Focused ESWT compared with platelet-rich plasma (PRP)} Included and excluded studies

Only one $\mathrm{RCT}^{27}$ with low risk of bias evaluated the effectiveness of focused ESWT compared with PRP injection up to 12-month follow-up. The comparison was indirect as both groups additionally received a standardised stretching and strengthening protocol for 2 weeks post treatment. The study did not provide information regarding the clinical diagnosis of PT, but they used ultrasound to identify proximal tendon anterior-posterior thickening with focal area of hypoechoic change and fibril discontinuity. Forty-six patients were enrolled with a mean age of 27 years, and mean duration of symptoms ranging from 17.6 to 18.9 months (table 2-see online supplementary table 2).

\section{Effects of interventions}

Effects of interventions regarding functional disability, pain reduction, self-perceived recovery and patient-rated pain reduction are presented in table 8. Comparison parameters, forest plots and criteria for quantitative synthesis are presented in detail in online supplementary appendix 4 .

\section{Conclusion and recommendations}

Very low level of evidence:

1. Focused ESWT produced comparable results to PRP injection at short-term follow-up (2 months) in VISA-P, self-perceived recovery and pain reduction.

2. PRP is more effective than focused ESWT at mid-term follow-up (6 months) in VISA-P, pain scores and patientrated pain reduction. 
Table 7 ESWT compared with control conservative management in patellar tendinopathy summary of evidence

\begin{tabular}{|c|c|c|c|c|c|c|}
\hline \multirow[b]{2}{*}{ Outcomes } & \multicolumn{2}{|c|}{ Comparisons } & \multirow[b]{2}{*}{ Relative effect $(95 \% \mathrm{CI})$} & \multirow[b]{2}{*}{$\begin{array}{l}\text { Patients / } \\
\text { studies (n) }\end{array}$} & \multirow[b]{2}{*}{$\begin{array}{l}\text { Quality of } \\
\text { evidence } \\
\text { (GRADE) }\end{array}$} & \multirow[b]{2}{*}{ Clinical significance } \\
\hline & $\begin{array}{l}\text { Average estimate / } \\
\text { assumed risk in the ESWT } \\
\text { group }\end{array}$ & $\begin{array}{l}\text { Average estimate /assumed } \\
\text { risk in the control group }\end{array}$ & & & & \\
\hline $\begin{array}{l}\text { VISA-P scores } \\
\text { Follow-up: 2-3 years }\end{array}$ & $\begin{array}{l}\text { ESWT: the mean } \pm \text { SD VISA-P } \\
\text { score was } 92.0 \pm 10.17\end{array}$ & $\begin{array}{l}\text { Control conservative: the } \\
\text { mean } \pm \text { SD VISA-P score was } \\
41.04 \pm 10.96\end{array}$ & $\begin{array}{l}\text { MD } 50.96 \\
\text { ( } 45.26 \text { to } 56.66 \text { ) } \\
\text { The difference was both } \\
\text { statistically and clinically } \\
\text { significant }\end{array}$ & $50 / 1$ & $\begin{array}{l}\bigoplus \bigoplus \\
\operatorname{Low}^{1,2,3}\end{array}$ & $\begin{array}{l}\text { Low level of evidence in } \\
\text { favour of focused ESWT } \\
\text { in VISA-P compared with } \\
\text { control conservative } \\
\text { treatment }\end{array}$ \\
\hline $\begin{array}{l}\text { Self-perceived recovery } \\
\text { Follow-up: 2-3 years }\end{array}$ & $\begin{array}{l}\text { ESWT: } 27 \text { of } 30(90 \%) \\
\text { participants reported } \\
\text { excellent and good outcomes }\end{array}$ & $\begin{array}{l}\text { Control conservative: } 12 \text { of } 24 \\
(50 \%) \text { participants reported } \\
\text { excellent and good outcomes }\end{array}$ & $\begin{array}{l}\text { OR } 9.00 \text { ( } 2.14 \text { to } 37.85) \\
\text { The difference was } \\
\text { statistically significant }\end{array}$ & $50 / 1$ & $\begin{array}{l}\bigoplus \bigoplus_{\text {Low }^{1,2,3}} \\
\text {. }\end{array}$ & $\begin{array}{l}\text { Low level of evidence in } \\
\text { favour of focused ESWT } \\
\text { compared with control } \\
\text { conservative treatment in } \\
\text { overall outcomes }\end{array}$ \\
\hline $\begin{array}{l}\text { VAS pain score* } \\
\text { Follow-up: } 2-3 \text { years }\end{array}$ & $\begin{array}{l}\text { ESWT: mean } \pm \text { SD pain score } \\
\text { was } 0.59 \pm 1.01\end{array}$ & $\begin{array}{l}\text { Control conservative: mean } \pm \text { SD } \\
\text { pain score was } 4.72 \pm 1.35\end{array}$ & $\begin{array}{l}\text { MD }-4.13 \\
\text { (-4.78 to } 3.48) \\
\text { The difference was both } \\
\text { statistically and clinically } \\
\text { significant }\end{array}$ & $50 / 1$ & $\begin{array}{l}\bigoplus \bigoplus_{\text {Low }^{1,2,3}}\end{array}$ & $\begin{array}{l}\text { Low level of evidence in } \\
\text { favour of focused ESWT } \\
\text { compared with control } \\
\text { conservative treatment in } \\
\text { VAS scores }\end{array}$ \\
\hline $\begin{array}{l}\text { Patient-rated pain } \\
\text { reduction** } \\
\text { Follow-up: } 2 \text { to } 3 \text { years }\end{array}$ & $\begin{array}{l}\text { ESWT: MD from baseline was } \\
5.41 \text { points }\end{array}$ & $\begin{array}{l}\text { Control conservative: MD from } \\
\text { baseline was } 0.66 \text { points }\end{array}$ & Not estimable & $50 / 1$ & $\mathrm{~N} / \mathrm{A}$ & $\begin{array}{l}\text { ESWT: very much } \\
\text { improved } \\
\text { Control conservative: no } \\
\text { change }\end{array}$ \\
\hline
\end{tabular}

*Pain scores are referred to pain at activities of daily living and load induced pain.

${ }^{* *}$ Cut-off points adjusted from Farrar et al. ${ }^{44}$

${ }^{1}$ Only one randomised controlled trial included in analysis.

${ }^{2}$ Level of evidence decreased due to different follow-up occasions for treatment groups.

${ }^{3}$ Level of evidence increased due to large magnitude of effect.

ESWT, extracorporeal shockwave therapy; GRADE, Grading of Recommendations Assessment, Development and Evaluation; MD, mean difference; N/A, not available; VAS, visual analogue scale.

3. PRP is more effective than focused ESWT at long-term follow-up (12 months) in VISA-P, self-perceived recovery, pain scores and patient-rated pain reduction.

Suggested protocol:

Not applicable due to substantial heterogeneity in PT studies' protocols.

\section{Focused ESWT compared with radial ESWT}

\section{Included and excluded studies}

Only one high-quality study with low risk of bias $\mathrm{RCT}^{29}$ evaluated the effectiveness of focused ESWT compared with radial ESWT at mid-term follow-up. The comparison was indirect as both groups additionally received a standardised eccentric exercise programme that started 2 weeks after the final ESWT session. The study performed analyses according to the intention-to-treat principle. Definition of PT was localised knee pain in the patellar tendon or its insertions related to activity, present for at least 3 months, palpation tenderness at the corresponding painful area and VISA-P score $<80$ at baseline. In case of doubt in diagnosis, ultrasound and MRI were used to rule out other knee pathologies. The study included 43 patients with PT, with a mean age of 31.1 years, and the mean duration of symptoms was 35.2 months (see online supplementary table 2).

\section{Effects of interventions}

Effects of interventions regarding functional disability, pain reduction, self-perceived recovery and patient-rated pain reduction are presented in table 9. Comparison parameters, forest plots and criteria for quantitative synthesis are presented in detail in online supplementary appendix 4.
Conclusion and recommendations

Very low level of evidence:

1. Focused ESWT produces comparable results to radial ESWT in patients with PT that received additive eccentric training at short-term and mid-term follow-up (up to 14 weeks) in VISA-P and pain scores.

Suggested protocol:

Not applicable.

\section{Proximal hamstring tendinopathy}

Included and excluded studies

Only one high-quality study with low risk of bias $\mathrm{RCT}^{31}$ evaluated the effectiveness of radial ESWT compared with traditional conservative treatment at 12-month follow-up. The control treatment consisted of rest, NSAIDs, physiotherapy and exercise programme for the last three weeks. The study was based on intention-to-treat principle, enrolled 40 patients with PHT with a mean age range from 23.7 to 24.2 years and mean duration of symptoms ranging from 19.6 to 21 months (online supplementary table 2). The diagnosis was based on relevant pain-provoking clinical testing and MRI. Pathology was defined as abnormalities at the proximal hamstring tendon substance, ill-defined pain, especially while performing sports activities or when sitting, in the ischial tuberosity that radiates distally towards the popliteal fossa.

\section{Effects of interventions}

Effects of interventions regarding functional disability, pain reduction, self-perceived recovery and patient-rated pain reduction are presented in table 10. Comparison parameters, forest plots and criteria for quantitative synthesis are presented in detail in online supplementary appendix 4. 


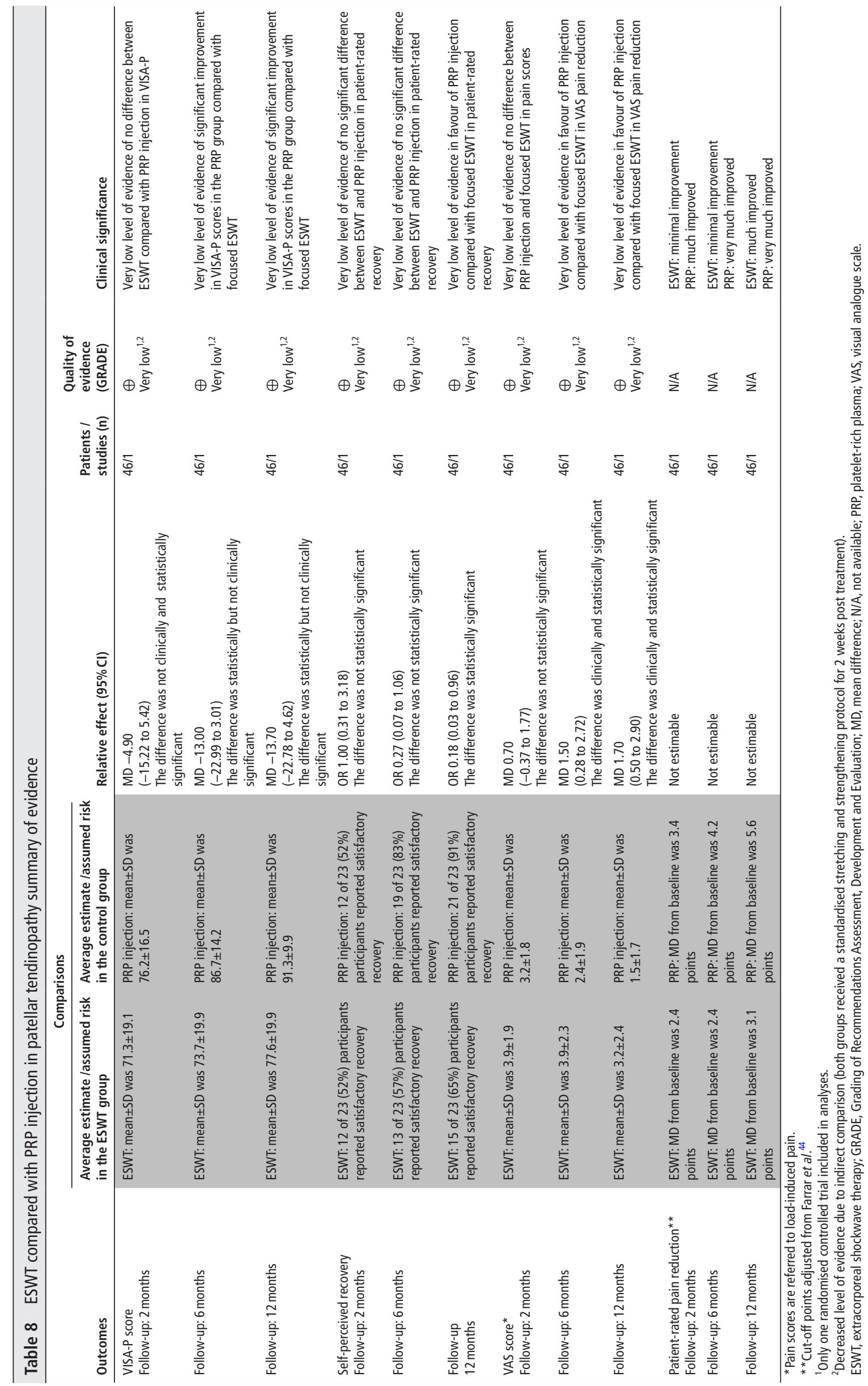


Table 9 Focused ESWT compared with radial ESWT in patellar tendinopathy summary of evidence

\begin{tabular}{|c|c|c|c|c|c|c|}
\hline \multirow[b]{2}{*}{ Outcomes } & \multicolumn{2}{|l|}{ Comparisons } & \multirow[b]{2}{*}{ Relative effect $(95 \% \mathrm{Cl})$} & \multirow[b]{2}{*}{$\begin{array}{l}\text { Patients / } \\
\text { studies (n) }\end{array}$} & \multirow[b]{2}{*}{$\begin{array}{l}\text { Quality of } \\
\text { evidence } \\
\text { (GRADE) }\end{array}$} & \multirow[b]{2}{*}{ Clinical significance } \\
\hline & $\begin{array}{l}\text { Average estimate / } \\
\text { assumed risk in } \\
\text { the ESWT group }\end{array}$ & $\begin{array}{l}\text { Average estimate / } \\
\text { assumed risk in } \\
\text { the control group }\end{array}$ & & & & \\
\hline $\begin{array}{l}\text { VISA-P score } \\
\text { Follow-up: } \\
7 \text { weeks }\end{array}$ & $\begin{array}{l}\text { Focused ESWT: mean } \pm \text { SD } \\
\text { was } 59.6 \pm 16.9\end{array}$ & $\begin{array}{l}\text { Radial } \\
\text { ESWT: mean } \pm \text { SD was } \\
53.5 \pm 21.5\end{array}$ & $\begin{array}{l}\text { MD } 6.10 \\
\text { (-5.43 to 17.63) } \\
\text { The difference was not clinically } \\
\text { and statistically significant }\end{array}$ & $43 / 1$ & $\begin{array}{l}\bigoplus \\
\text { Very low }\end{array}$ & $\begin{array}{l}\text { Very low level of evidence of no } \\
\text { difference between focused and } \\
\text { radial ESWT in VISA-P scores }\end{array}$ \\
\hline Follow-up: 14 weeks & $\begin{array}{l}\text { Focused ESWT: mean } \pm \text { SD } \\
\text { was } 63.6 \pm 24.2\end{array}$ & $\begin{array}{l}\text { Radial } \\
\text { ESWT: mean } \pm S D \text { was } \\
58.4 \pm 22.1\end{array}$ & $\begin{array}{l}\text { MD } 5.20 \\
\text { (-8.67 to 19.07) } \\
\text { The difference was not clinically } \\
\text { and statistically significant }\end{array}$ & $43 / 1$ & $\begin{array}{l}\bigoplus \\
\text { Very low }\end{array}$ & $\begin{array}{l}\text { Very low level of evidence of no } \\
\text { difference between focused and } \\
\text { radial ESWT in VISA-P scores }\end{array}$ \\
\hline $\begin{array}{l}\text { VAS score* } \\
\text { Follow-up: } 7 \text { weeks }\end{array}$ & $\begin{array}{l}\text { Focused ESWT: mean } \pm \text { SD } \\
\text { was } 3.2 \pm 3.5\end{array}$ & $\begin{array}{l}\text { Radial } \\
\text { ESWT: mean } \pm S D \text { was } \\
3.6 \pm 2.6\end{array}$ & $\begin{array}{l}\text { MD }-0.40 \\
(-0,25 \text { to } 1.45) \\
\text { The difference was not clinically } \\
\text { and statistically significant }\end{array}$ & $43 / 1$ & $\begin{array}{l}\bigoplus \\
\text { Very low }{ }^{1,2}\end{array}$ & $\begin{array}{l}\text { Very low level of evidence of no } \\
\text { difference between focused and } \\
\text { radial ESWT in pain scores }\end{array}$ \\
\hline Follow-up: 14 weeks & $\begin{array}{l}\text { Focused ESWT: mean } \pm \text { SD } \\
\text { was } 3.4 \pm 3.5\end{array}$ & $\begin{array}{l}\text { Radial } \\
\text { ESWT: mean } \pm S D \text { was } \\
3.0 \pm 2.7\end{array}$ & $\begin{array}{l}\text { MD } 0.40 \\
(-1.47 \text { to } 2.27) \\
\text { The difference was not clinically } \\
\text { and statistically significant }\end{array}$ & $43 / 1$ & $\begin{array}{l}\bigoplus \\
\text { Very low }\end{array}$ & $\begin{array}{l}\text { Very low level of evidence of no } \\
\text { difference between focused and } \\
\text { radial ESWT in pain scores }\end{array}$ \\
\hline $\begin{array}{l}\text { Patient-ratedpain } \\
\text { reduction** } \\
\text { Follow-up: } 7 \text { weeks }\end{array}$ & $\begin{array}{l}\text { Focused ESWT: MD from } \\
\text { baseline was } 1.2 \text { points }\end{array}$ & $\begin{array}{l}\text { Radial ESWT: MD from } \\
\text { baseline was } 0.5 \text { points }\end{array}$ & Not estimable & $43 / 1$ & $\mathrm{~N} / \mathrm{A}$ & $\begin{array}{l}\text { ESWT: much improved } \\
\text { PRP: minimally improved }\end{array}$ \\
\hline Follow-up: 14 weeks & $\begin{array}{l}\text { Focused ESWT: MD from } \\
\text { baseline was } 1.0 \text { points }\end{array}$ & $\begin{array}{l}\text { Radial ESWT: MD from } \\
\text { baseline was } 1.1 \text { points }\end{array}$ & Not estimable & $43 / 1$ & $\mathrm{~N} / \mathrm{A}$ & $\begin{array}{l}\text { ESWT: minimal improved } \\
\text { PRP: much improved }\end{array}$ \\
\hline
\end{tabular}

*Pain scores are referred to 10 single-leg decline squats on injured leg.

${ }^{* *}$ Cut-off points adjusted from Farrar et al. ${ }^{44}$

${ }^{1}$ Only one randomised controlled trial included in analyses.

${ }^{2}$ Decreased level of evidence due to indirect comparison (both groups received a standardised eccentric training programme).

ESWT, extracorporeal shockwave therapy; GRADE, Grading of Recommendations Assessment, Development and Evaluation; MD, mean difference; N/A, not available; PRP,

platelet-rich plasma.

\section{Conclusion and recommendations}

Moderate level of evidence:

1. Radial ESWT produces superior results to conservative treatment (consisted of rest, NSAIDs, physiotherapy, and exercise programme) in patients with PHT at short-term, mid-term and long-term follow-up (up to 12 months) in Nirschl rating scale, self-perceived recovery, pain scores and patient-rated pain reduction.

2. Conservative treatment consisting of rest, NSAIDs, physiotherapy and exercise programme is not effective for patients with PHT.

Suggested protocol:

Using radial ESWT deliver 2500 impulses at four bars (energy flux density $0.18 \mathrm{~mJ} / \mathrm{mm}^{2}$ ) at $10 \mathrm{~Hz}$ for four sessions at weekly intervals.

\section{Additional analyses}

Sensitivity analyses did not reveal any significant differences with the results of the present systematic review. None of the approaches examined resulted in a change in direction of the effect in any condition evaluated. Inclusion of low-quality and/or non-randomised controlled studies affected only the magnitude of effect (overestimation). One of these analyses is presented in online supplementary appendix 5 .

\section{DISCUSSION}

\section{Summary of main findings and clinical interpretation}

To date, 31 studies have been published assessing ESWT in lower limb conditions assessed, among which 15 were RCTs.

\section{Mid-portion AT}

Low and very low level of evidence suggests that radial ESWT produces equal results with eccentric loading, superior results compared with wait-and-see policy and superior results when combined with eccentric training compared with eccentric training alone, at mid-term follow-up.

Clinically eccentric loading is considered the gold-standard non-operative treatment for mid-portion $\mathrm{AT},{ }^{64}$ but here it is seen that low-energy ESWT showed equal results in the short term. It is noted however that there are conflicting outcomes when compared with wait-and-see policy outcomes. ${ }^{7}$ Further, despite ESWT in combination with eccentric loading showing superior results in pain and function compared with eccentric training alone, ${ }^{6}$ the significance was seen only in functional scores but not in pain reduction.

\section{Insertional AT}

Low-level evidence suggests that three sessions of radial ESWT is more effective in functional outcome and pain reduction than eccentric training at mid-term follow-up.

The clinical significance of these results is further supported by the patient-rated improvement in pain reduction.

\section{Mixed non-specified AT}

Very low level of evidence suggests that ESWT is no better than placebo shockwave at short-term follow-up in self-perceived recovery and pain reduction. It is noted that effect size calculation was not possible from one study ${ }^{15}$ due to insufficient data.

Conversely, inconsistent findings were found in function between patients treated with ESWT or placebo ESWT as 


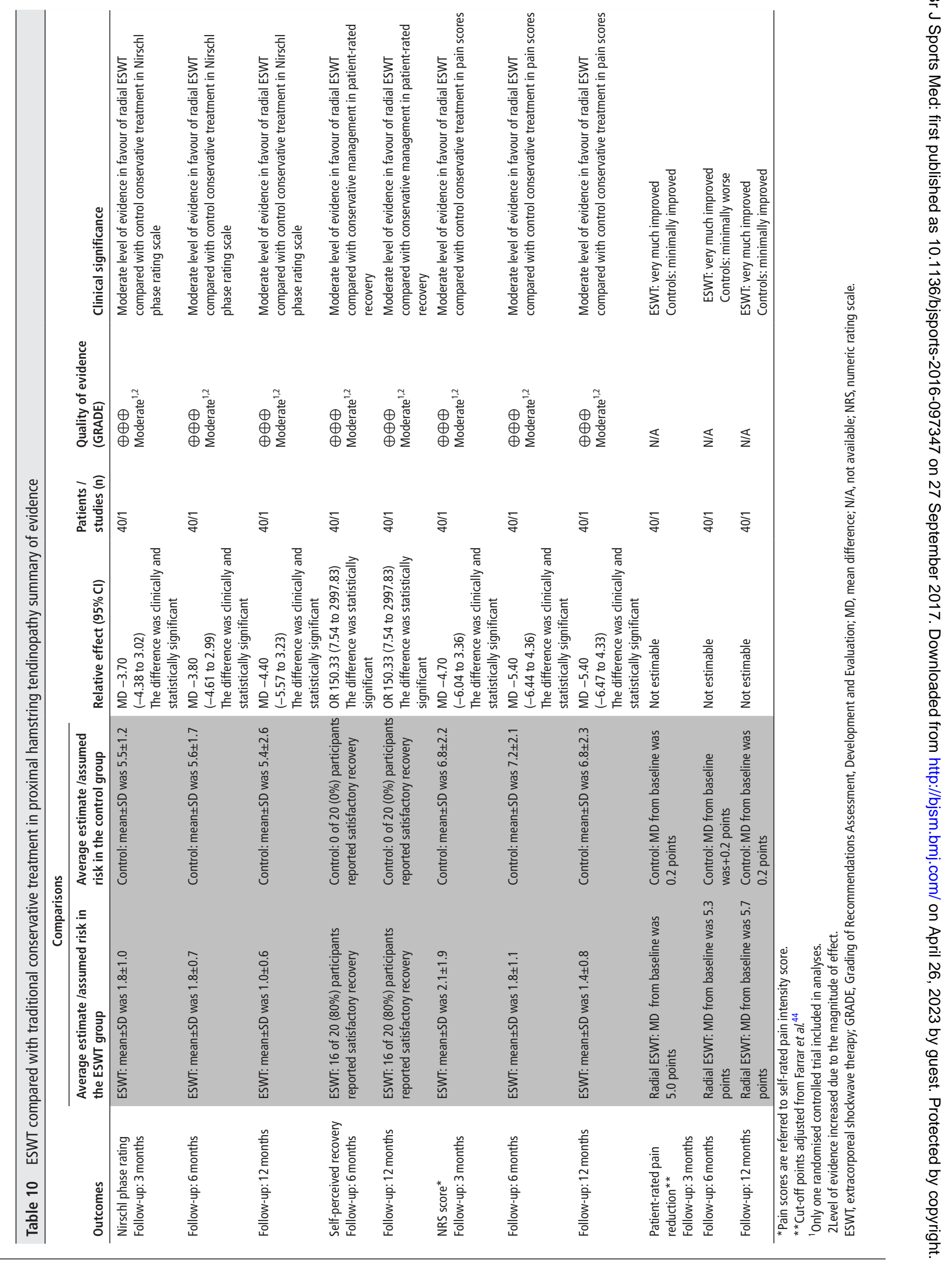


indicated by American Orthopaedic Foot and Ankle Society score ${ }^{14}$ and functional index of lower limb activity. ${ }^{15}$ Two possible confounding factors may explain these inconsistent results: the groups' age and the treatment protocols. The mean age of ESWT group in the Costa $e ~_{a l} l^{14}$ study was significantly older than their control group and both groups of the Rasmussen et a ${ }^{15}$ study. Furthermore, Costa et al ${ }^{14}$ used lower total energy flux density, less sessions and longer (monthly) intervals compared with the treatment protocol used by Rasmussen et al. ${ }^{15}$ The differences in treatment protocols, along with the use of generic outcome measures for function assessment, may partially explain these results and the inconsistencies in patient-rated pain reduction. We suggest that the sample configuration in these studies raises several considerations that will be discussed below.

\section{Greater trochanteric pain syndrome}

Low level of evidence suggests that corticosteroid injection is superior to therapeutic intervention in the short term. Low level of evidence showed that at mid-term and long-term follow-up radial ESWT is more effective than corticosteroid injection and produced comparable results to physiotherapy, stretching and strengthening.

Conflicting evidence exists regarding the short-term effectiveness of ESWT (1 month). Interestingly in the study of Rompe et $a l,{ }^{17}$ in contrast to the study of Furia $e t a l,{ }^{16}$ the ESWT group did not present statistically or clinically significant pain reduction at 1 month with a patient rating of 'no change'. ${ }^{44}$ By reviewing the demographic data in both studies, there were no significant differences in age and symptom duration among ESWT groups. The difference in ESWT protocol probably could partially explain the differences between the groups, with the major difference being the number of sessions (one compared with three). Furthermore, the lack of clarity in the reporting of the non-operative conservative treatments prevented a meaningful interpretation of the findings between the studies. ${ }^{16} 17$

The short-term effect of corticosteroid injection disappeared with time providing no benefit in reducing pain or improving function in GTPS at mid-term and long-term follow-up. ${ }^{17}$ This result was in accordance with several studies demonstrating only the short-term effect of corticosteroid injections in a number of musculoskeletal conditions. ${ }^{65-67}$ Accordingly, ESWT can be an effective mid-term and a feasible long-term treatment option for patients with GTPS. Inconsistencies between studies limit the external validity of the results regarding the short-term effectiveness of ESWT.

\section{Medial tibial stress syndrome}

No evidence for ESWT due to extremely small sample size in one study ${ }^{20}$ and non-randomised controlled study design in two studies. ${ }^{18} 19$

Both non-randomised studies ${ }^{18} 19$ reported favourable results for the ESWT group. The most striking difference between studies was the ESWT protocol used in terms of total energy flux. One study ${ }^{19}$ used the same low-energy protocol of radial ESWT for three sessions (energy flux density $0.1 \mathrm{~mJ} /$ $\mathrm{mm}^{2}$ ), while the other ${ }^{18}$ used a graded energy protocol of focused ESWT for five sessions (energy flux density from 0.1 to $0.3 \mathrm{~mJ} / \mathrm{mm}^{2}$ ), resulting in more than the double total energy flux. Contradictory results at short-term follow-up were presented by the only $\mathrm{RCT}^{20}$ that used the same ESWT protocol as a non-randomised study. ${ }^{18}$ Several considerations are raised regarding the effectiveness of ESWT as well as the dose of the mechanical energy to be transferred. According to the data presented in this probably underpowered study, the sham group had better results in terms of pressure-induced pain and distance of pain-free running compared with the ESWT group. Data from these three studies suggest that the types of regimens and the configuration of the sample used can significantly influence outcome. The utility for ESWT in MTSS remains to be seen. Future randomised controlled studies with sufficient sample sizes are needed to clearly assess the effectiveness of ESWT and define the parameters of the most effective protocol.

\section{Patellar tendinopathy}

Moderate-level evidence suggests no difference between focused ESWT and placebo ESWT at short-term and mid-term (5-6 months) follow-up in pain and function. On the contrary, low-level evidence suggests that focused ESWT is superior to control conservative treatment (NSAID, physiotherapy, exercise, knee strap, modification of activity levels) at long-term follow-up (2-3 years) in functional and pain outcomes. Very low-level evidence suggests that focused ESWT produces comparable results to PRP injection along with stretching and strengthening at short-term follow-up, but PRP is more effective than ESWT at mid-term and long-term follow-up on VISA-P, pain scores and patient-rated pain reduction. Very low level of evidence suggests that focused ESWT produces comparable results to radial ESWT in patients with PT that received additive eccentric training at short-term and mid-term follow-up.

From the clinical perspective, conflicting evidence from two $\mathrm{RCTs}^{25}{ }^{26}$ with comparison of ESWT and another RCT ${ }^{30}$ that used additive eccentric training was drawn for the effectiveness of ESWT compared with control/placebo. Zwerver et al ${ }^{25}$ argued that the inconsistent findings could be attributed to patient characteristics. The athletes in the Zwerver $e a^{25}$ study had a mean VISA-P score of 60 and mean duration of symptoms of 8 months compared with the recreational athletes of Wang et al, ${ }^{26}$ which had a mean VISA-P score of 40 and mean duration of symptoms of $>12$ months. If interpreted according to the continuum model of tendon pathology, ${ }^{68}$ the athletes in one study were probably suffering from reactive tendinopathy or early tendon disrepair in contrast to athletes in a more degenerative stage of tendinopathy. Additionally, it is possible that these results could be attributed to the ESWT protocol used and the fact that the athletes continued participating in their sport activities in the Zwerver et al ${ }^{25}$ study.

We suggest that these results may demonstrate preliminary evidence for a non-linear dose-response relationship for ESWT with both the lowest and highest levels of total energy flux resulting in less improvement. Specifically, the placebo group in Zwerver $e$ e $\mathrm{al}^{25}$ (lowest total energy flux: $180 \mathrm{~mJ} / \mathrm{mm}^{2}$ ) and the active group in the same study (highest total energy flux: estimated between 600 and $3480 \mathrm{~mJ} / \mathrm{mm}^{2}$ ) had the lowest patientrated improvements. The highest improvement (long-term follow-up) was seen in the study of Wang et al, ${ }^{26}$ who applied approximately $270 \mathrm{~mJ} / \mathrm{mm}^{2}$. While we cannot draw direct evidence from the results of Thijs $e t a l^{30}$ due to indirect comparison, the minimum and maximum energy flux they used was in accordance with the study of Zwerver et al..$^{25}$ In this study, the placebo ESWT group received approximately $180 \mathrm{~mJ} / \mathrm{mm}^{2}$ while the ESWT group received $>600 \mathrm{~mJ} / \mathrm{mm}^{2}$ similar to the Zwerver et $^{25} \mathrm{l}^{25}$ study.

Limited evidence suggests no difference in the effectiveness between radial and focused ESWT along with an adjunct eccentric training programme in functional and pain scores 
at mid term. ${ }^{29}$ There are only two studies ${ }^{29} 30$ (one being one arm of Thijs $e a^{30}$ ) combining eccentric loading and ESWT in patients with PT and both reported significant improvement. However, van der Worp et al ${ }^{29}$ questioned the significance of these results because the difference in VISA-P scores did not reach the cut-off point for MCID (15 points). ${ }^{55} 69$ Interestingly, the VISA-P scores in the focused ESWT arm of both studies were comparable. Clinically it is of importance to ascertain if ESWT (focused or radial) may mitigate the positive effects of eccentric training in PT. Studies that assessed eccentric training alone $\mathrm{e}^{70-72}$ and included PT patients with similar duration of symptoms and follow-up reported consistent improvements in VISA-P scores that exceeded 20 points. Further studies are needed to assess different protocols of ESWT (energy and sessions) as an adjunct to eccentric load, as a specific single application low-energy treatment scheme was found to be effective. ${ }^{26}$

Given these data, the most effective ESWT protocol (sessions, dose, duration) is likely yet to be elucidated.

\section{Proximal hamstring tendinopathy}

Moderate-level evidence suggests that radial ESWT produces superior results to conservative treatment up to long-term follow-up (up to 12 months) in both functional and pain outcomes.

Using a protocol of four sessions over 4 weeks with medium energy, ESWT significantly decreased pain at 1 week follow-up. ${ }^{31}$ The reduction of pain persisted for 3 months and then remained stable up to 12 months follow-up ('very much improved'). In contrast, the control group's condition according to patients' estimation ${ }^{44}$ deteriorated in each follow-up assessment, suggesting that the traditional conservative therapy used was ineffective. The high effect sizes calculated probably overestimated the effect due to the small numbers included in the study or probably because of the ineffectiveness of control treatment regimen. The overestimation was more evident in the OR calculation as $35 \%$ of the control group reported worsening in symptoms at 3 months, $45 \%$ at 6 months and $40 \%$ at 12 months, resulting in $25 \%$ loss at long-term follow-up. Based on these data, moderate evidence suggests that rest, NSAIDs, ultrasound, transverse friction massage, stretching and strengthening are not recommended in patients with chronic PHT.

Despite this study indicating that ESWT is an effective and promising treatment option for chronic PHT, the external validity of these results is limited by the relatively small sample size. Future studies are needed not only to evaluate further its effectiveness, but to compare ESWT with other more appropriate treatments for chronic PHT.

\section{Strengths and limitations}

This systematic review has documented the outcomes for a relatively large number of subjects (1847) included in relatively highquality trials spread across conditions assessed and we suggest that the inclusion of the interpretation of effect sizes for pain reduction in patient-centred terms is a strength. Unfortunately, there are no occasions where multiple high-quality studies exist for a single pathology, hence for any individual pathology there are low and very low levels of evidence. We acknowledge the following as limitations: the study was not registered on the International prospective register of systematic reviews, and a funnel plot for assessment of publication bias was not created due to the small number of included studies for each individual pathology.
The poor correlation of the two different quality assessment tools used probably can explain the inconsistent results between the present and a recent systematic review, ${ }^{34}$ at least for AT, PT and GTPS. This highlights the importance of a research consensus in terms of methodological standardisation, guidelines in reporting and applicability/suitability of selected quality assessment tools in terms of study design. It is noted that our use of the GRADE ranking for level of evidence has likely contributed to the marked difference in overall conclusions drawn.

A limitation of research in this area and a possible bias is that a relatively small number of research groups account for the majority of research (approximately half of the studies included in quantitative analysis here) in this area. Another limitation relates to the inclusion criteria of studies which are seen to be variable and somewhat arbitrary. Increasingly it is noted that there is a poor association between radiologically identified abnormalities and pathology. ${ }^{63}{ }^{64}$ Similarly, the variability and inaccuracy associated with clinical examination make for potentially insurmountable difficulties in the standardisation of treatment groups. Finally, the variability of the treatment protocols (in terms of energy delivered and total number of sessions) as well as the included patients makes generalisability difficult.

\section{Future research suggestions and recommendations}

Research to date has provided preliminary evidence for the effectiveness or not of ESWT; however, there is still a need for high-quality RCTs to discover the exact dose-response relation and its efficacy in larger sample sizes. It is also noted that clinicians would rarely provide ESWT as a monotherapy; rather it is often recommended that an individualised intervention should be provided depending both on the individual pathology (eg, insertional AT compared with non-insertional, reactive compared with degenerative) and the individual patient (non-athlete compared with high-level athlete, in-season compared with out of season, presence of comorbidities or not). It remains to be seen which factors in the patient's presentation are truly confounding and what aspects of the intervention need to be modified to maximise the outcomes. We recommend, as a starting point, that minimum reporting standards be developed in terms of diagnostic classification criteria, outcomes, baseline measures, confounding factors (subject-specific) and aspects of the treatment applied. A future research suggestion is a network meta-analysis that would allow comparison of different treatment options to ESWT, once sufficient studies are available for a reasonable analysis.

Evidence suggests that exercise interventions are effective in lower limb conditions such as tendinopathy, ${ }^{73}$ but their effectiveness is limited to a subgroup of patients. Given the conflicting, low level of evidence or no evidence for more aggressive treatment approaches, such as PRP or corticosteroid injections, ${ }^{73}$ we suggest that ESWT is a suitable alternative option in lower limb conditions under investigation unresponsive to other conservative interventions.

\section{CONCLUSION}

There is a relatively large body of evidence spread across individual conditions assessed providing mainly low-level evidence for the efficacy of ESWT in lower limb conditions at short-term, mid-term and long-term follow-up. Caution needs to be exercised however in the clinical interpretation of these findings as it is likely that patient-specific individual confounding factors may 
What is the evidence of shockwave therapy in lower limb conditions?

- Moderate-level evidence suggests that shockwave therapy is no better than placebo shockwave in patellar tendinopathy. This needs to be further investigated as preliminary evidence exists for a non-linear dose-response relationship for extracorporeal shockwave therapy with both the lowest and highest levels of total energy flux.

- Moderate-level evidence suggests that shock wave is an effective intervention with large effect size in proximal hamstring tendinopathy.

- Low-level evidence suggests that shockwave therapy is an effective intervention for Achilles tendinopathy, as well as for greater trochanteric pain syndrome.

- There is no evidence for the effectiveness of shockwave therapy in medial tibial stress syndrome.

\section{Future research}

- We suggest that future systematic reviews include the interpretation of effect sizes for pain reduction in patientcentered terms.

- Shockwave therapy is rarely used as a monotherapy. Future studies should evaluate more clinically oriented, as well as individualised protocols, in terms of clinical effectiveness.

- A research consensus in terms of methodological standardisation, guidelines in reporting and applicability/ suitability of selected quality assessment tools in terms of study design is essential.

have a significant effect on ultimate treatment outcomes, and these confounding aspects have not been fully examined.

Contributors All authors contributed to this work and the authorship of this manuscript. VK planned, coordinated the idea, conducted the search, analysed results, wrote and reviewed the manuscript. RW coordinated the idea, analysed the results, provided writing content and reviewed. AT conducted the search, wrote and reviewed the manuscript. NM provided writing and review support.

\section{Competing interests None declared.}

Provenance and peer review Not commissioned; externally peer reviewed.

C Article author(s) (or their employer(s) unless otherwise stated in the text of the article) 2018. All rights reserved. No commercial use is permitted unless otherwise expressly granted.

\section{REFERENCES}

1 Notarnicola A, Pesce V, Vicenti G, et al. SWAAT study: extracorporeal shock wave therapy and arginine supplementation and other nutraceuticals for insertional Achilles tendinopathy. Adv Ther 2012;29:799-814.

2 Perlick L, Schiffmann R, Kraft CN, et al. Extracorporal shock wave treatment of the achilles tendinitis: Experimental and preliminary clinical results. Z Orthop Ihre Grenzgeb 2002; 140:275-80.

3 Furia JP. High-energy extracorporeal shock wave therapy as a treatment for insertional achilles tendinopathy. Am J Sports Med 2006;34:733-40.

4 Rompe JD, Furia J, Maffulli N. Eccentric loading compared with shock wave treatment for chronic insertional achilles tendinopathy. A randomized, controlled trial. J Bone Joint Surg Am 2008;90:52-61.

5 Furia JP. High-energy extracorporeal shock wave therapy as a treatment for chronic noninsertional achilles tendinopathy. Am J Sports Med 2008;36:502-8.

6 Rompe JD, Furia J, Maffulli N. Eccentric loading versus eccentric loading plus shockwave treatment for midportion achilles tendinopathy: a randomized controlled trial. Am J Sports Med 2009;37:463-70.

7 Rompe JD, Nafe B, Furia JP, et al. Eccentric loading, shock-wave treatment, or a wait-and-see policy for tendinopathy of the main body of tendo Achillis: a randomized controlled trial. Am J Sports Med 2007;35:374-83.
8 Fridman R, Cain JD, Weil L, et al. Extracorporeal shockwave therapy for the treatment of Achilles tendinopathies: a prospective study. J Am Podiatr Med Assoc 2008;98:466-8.

9 Lakshmanan P, O'Doherty DP. Chronic achilles tendinopathy: treatment with extracorporeal shock waves. Foot and Ankle Surgery 2004;10:125-30.

10 Lohrer H, Schöll J, Arentz S. Achilles tendinopathy and patellar tendinopathy. results of radial shockwave therapy in patients with unsuccessfully treated tendinoses. Sportverletz Sportschaden 2002;16:108-14.

11 Saxena A, Ramdath S, O'Halloran P, et al. Extra-corporeal pulsed-activated therapy ("EPAT" sound wave) for Achilles tendinopathy: a prospective study. J Foot Ankle Surg 2011;50:315-9.

12 Taylor J, Dunkerley S, Silver D, et al. Extracorporeal shockwave therapy (ESWT) for refractory Achilles tendinopathy: a prospective audit with 2-year follow up. Foot 2016;26:23-9.

13 Vulpiani MC, Trischitta D, Trovato P, et al. Extracorporeal shockwave therapy (ESWT) in achilles tendinopathy. A long-term follow-up observational study. J Sports Med Phys Fitness 2009;49:171-6.

14 Costa ML, Shepstone L, Donell ST, et al. Shock wave therapy for chronic Achilles tendon pain: a randomized placebo-controlled trial. Clin Orthop Relat Res 2005;440:199-204.

15 Rasmussen S, Christensen M, Mathiesen I, et al. Shockwave therapy for chronic Achilles tendinopathy: a double-blind, randomized clinical trial of efficacy. Acta Orthop 2008;79:249-56.

16 Furia JP, Rompe JD, Maffulli N. Low-energy extracorporeal shock wave therapy as a treatment for greater trochanteric pain syndrome. Am J Sports Med 2009;37:1806-13

17 Rompe JD, Segal NA, Cacchio A, et al. Home training, local corticosteroid injection, or radial shock wave therapy for greater trochanter pain syndrome. Am J Sports Med 2009;37:1981-90.

18 Moen MH, Rayer S, Schipper M, et al. Shockwave treatment for medial tibial stress syndrome in Athletes; a prospective controlled study. Br J Sports Med 2012;46:253-7.

19 Rompe JD, Cacchio A, Furia JP, et al. Low-energy extracorporeal shock wave therapy as a treatment for medial tibial stress syndrome. Am J Sports Med 2010;38:125-32

20 Newman P, Waddington G, Adams R. Shockwave treatment for medial tibial stress syndrome: a randomized double blind sham-controlled pilot trial. J Sci Med Sport. In Press. 2017;20:220-4.

21 Peers KH, Lysens RJ, Brys P, et al. Cross-sectional outcome analysis of athletes with chronic patellar tendinopathy treated surgically and by extracorporeal shock wave therapy. Clin J Sport Med 2003;13:79-83.

22 Taunton JE, Taunton KM, Khan KM. Treatment of patellar tendinopathy with extracorporeal shock wave therapy. B C Med J 2003;45:500-7.

23 Vulpiani MC, Vetrano M, Savoia V, et al. Jumper's knee treatment with extracorporeal shock wave therapy: a long-term follow-up observational study. J Sports Med Phys Fitness 2007;47:323-8.

24 Zwerver J, Dekker F, Pepping GJ. Patient guided Piezo-electric Extracorporeal Shockwave Therapy as treatment for chronic severe patellar tendinopathy: A pilot study. J Back Musculoskelet Rehabil 2010;23:111-5.

25 Zwerver J, Hartgens F, Verhagen E, et al. No effect of extracorporeal shockwave therapy on patellar tendinopathy in jumping athletes during the competitive season: a randomized clinical trial. Am J Sports Med 2011;39:1191-9.

26 Wang CJ, Ko JY, Chan YS, et al. Extracorporeal shockwave for chronic patellar tendinopathy. Am J Sports Med 2007;35:972-8.

27 Vetrano M, Castorina A, Vulpiani MC, et al. Platelet-rich plasma versus focused shock waves in the treatment of jumper's knee in athletes. Am J Sports Med 2013;41:795-803.

28 Furia JP, Rompe JD, Cacchio A, et al. A single application of low-energy radial extracorporeal shock wave therapy is effective for the management of chronic patellar tendinopathy. Knee Surg Sports Traumatol Arthrosc 2013;21:346-50.

29 van der Worp H, Zwerver J, Hamstra M, et al. No difference in effectiveness between focused and radial shockwave therapy for treating patellar tendinopathy: a randomized controlled trial. Knee Surg Sports Traumatol Arthrosc 2014;22:2026-32.

30 Thijs KM, Zwerver J, Backx FJ, et al. Effectiveness of Shockwave Treatment Combined with Eccentric training for patellar tendinopathy: a Double-Blinded Randomized Study. Clin J Sport Med 2017;27:89-96. Epub ahead of print.

31 Cacchio A, Rompe JD, Furia JP, et al. Shockwave therapy for the treatment of chronic proximal hamstring tendinopathy in professional Athletes. Am J Sports Med 2011;39:146-53.

32 Moher D, Liberati A, Tetzlaff J, et al. Preferred reporting items for systematic reviews and meta-analyses: the PRISMA statement. BMJ 2009;339:b2535-6.

33 Larsson ME, Käll I, Nilsson-Helander K. Treatment of patellar tendinopathy--a systematic review of randomized controlled trials. Knee Surg Sports Traumatol Arthrosc 2012;20:1632-46.

34 Mani-Babu S, Morrissey D, Waugh C, et al. The effectiveness of extracorporeal shock wave therapy in lower limb tendinopathy: a systematic review. Am J Sports Med 2015;43:752-61.

35 Wiegerinck Jl, Kerkhoffs GM, van Sterkenburg MN, et al. Treatment for insertional achilles tendinopathy: a systematic review. Knee Surg Sports Traumatol Arthrosc 2013;21:1345-55. 
36 Higgins JPT, Green S. Cochrane Handbook for Systematic Reviews of Interventions. Version 5.1.0 ed: The Cochrane Collaboration 2011.

37 Al-Abbad H, Simon JV. The effectiveness of extracorporeal shock wave therapy on chronic achilles tendinopathy: a systematic review. Foot Ankle Int 2013;34:33-41.

38 Schmitz C, Császár NB, Milz S, et al. Efficacy and safety of extracorporeal shock wave therapy for orthopedic conditions: a systematic review on studies listed in the PEDro database. Br Med Bull 2015;116:Idv047-38.

39 Speed CA. Extracorporeal shock-wave therapy in the management of chronic softtissue conditions. J Bone Joint Surg Br 2004;86:165-71.

40 Winters M, Eskes M, Weir A, et al. Treatment of medial tibial stress syndrome: a systematic review. Sports Med 2013;43:1315-33.

41 Korakakis V, Whiteley R. The effectiveness of ESWT in Lower Limb Tendinopathy: letter to the Editor. Am J Sports Med 2015;43:NP43-NP44.

42 Speed C. A systematic review of shockwave therapies in soft tissue conditions: focusing on the evidence. Br J Sports Med 2014;48:1538-42.

43 Magnussen RA, Dunn WR, Thomson AB. Nonoperative treatment of midportion achilles tendinopathy: a systematic review. Clin J Sport Med 2009;19:54-64.

44 Farrar JT, Young JP, LaMoreaux L, et al. Clinical importance of changes in chronic pain intensity measured on an 11-point numerical pain rating scale. Pain 2001;94:149-58.

45 Ostelo RW, Deyo RA, Stratford P, et al. Interpreting change scores for pain and functional status in low back pain: towards international consensus regarding minimal important change. Spine 2008;33:90-4.

46 Robinson JM, Cook JL, Purdam C, et al. The VISA-A questionnaire: a valid and reliable index of the clinical severity of Achilles tendinopathy. Br J Sports Med 2001;35:335-41.

47 Visentini PJ, Khan KM, Cook JL, et al. The VISA score: an index of severity of symptoms in patients with jumper's knee (patellar tendinosis). J Sci Med Sport 1998;1:22-8.

48 The Cochrane Collaboration. Review Manager (RevMan. 5.3 ed: The Nordic Cochrane Centre, 2014.

49 Reeves B, Deeks J, Higgins J, et al. Including non-randomized studies (Chapter 13). In: Higgins JPT, Green S, eds. Cochrane Handbook for Systematic Reviews of Interventions. version 5.1.0. the Cochrane Collaboration, 2011.

50 Downs SH, Black N. The feasibility of creating a checklist for the assessment of the methodological quality both of randomised and non-randomised studies of health care interventions. J Epidemiol Community Health 1998;52:377-84.

51 Hooper P, Jutai JW, Strong G, et al. Age-related macular degeneration and low-vision rehabilitation: a systematic review. Can J Ophthalmol 2008;43:180-7.

52 Higgins JP, Thompson SG, Deeks JJ, et al. Measuring inconsistency in meta-analyses. BMJ 2003;327:557-60.

53 Schroll JB, Moustgaard R, Gøtzsche PC. Dealing with substantial heterogeneity in Cochrane reviews. Cross-sectional study. BMC Med Res Methodo/ 2011;11:22

54 Hernandez-Sanchez S, Hidalgo MD, Gomez A, et al. Responsiveness of the VISA-P scale for patellar tendinopathy in athletes. Br J Sports Med 2014:48:453-7.

55 Wageck BB, de Noronha M, Lopes AD, et al. Cross-cultural adaptation and measurement properties of the Brazilian Portuquese Version of the Victorian Institute of Sport Assessment-Patella (VISA-P) scale. J Orthop Sports Phys Ther 2013:43:163-71.

56 Kemp JL, Collins NJ, Roos EM, et al. Psychometric properties of patient-reported outcome measures for hip arthroscopic surgery. Am J Sports Med 2013:41:2065-73.
57 McCormack J, Underwood F, Slaven E, et al. The minimum clinically important difference on the visa-a and lefs for patients with insertional achilles tendinopathy. Int J Sports Phys Ther 2015;10:639-44.

58 de Vos RJ, Weir A, van Schie HT, et al. Platelet-rich plasma injection for chronic Achilles tendinopathy: a randomized controlled trial. JAMA 2010;303:144-9.

59 Sayana MK, Maffulli N. Eccentric calf muscle training in non-athletic patients with achilles tendinopathy. J Sci Med Sport 2007;10:52-8.

60 Overdevest GM, Jacobs W, Vleggeert-Lankamp C T, et al. Effectiveness of posterior decompression techniques compared with conventional laminectomy for lumbar stenosis. Cochrane Database Syst Rev 2015;3:Cd010036.

61 Atkins D, Best D, Briss PA, et al. Grading quality of evidence and strength of recommendations. BMJ 2004;328:1490

62 Furia JP. Extrakorporale Stoßwellentherapie zur Behandlung der Achillessehnentendinopathie. Orthopade 2005;34:571-8.

63 Johansson K, Lempainen L, Sarimo J, et al. Macroscopic anomalies and pathologica findings in and around the Achilles Tendon: observations from 1661 Operations during a 40-Year period. Orthop J Sports Med 2014:2:2325967114562371.

64 Allison GT, Purdam C. Eccentric loading for achilles tendinopathy--strengthening or stretching? Br J Sports Med 2009;43:276-9.

65 Barr S, Cerisola FL, Blanchard V. Effectiveness of corticosteroid injections compared with physiotherapeutic interventions for lateral epicondylitis: a systematic review. Physiotherapy 2009;95:251-65.

66 Blanchard V, Barr S, Cerisola FL. The effectiveness of corticosteroid injections compared with physiotherapeutic interventions for adhesive capsulitis: a systematic review. Physiotherapy 2010;96:95-107

67 Peterson C, Hodler J. Evidence-based radiology (part 2): Is there sufficient research to support the use of therapeutic injections into the peripheral joints? Skeletal Radiol 2010:39:11-18.

68 Cook JL, Purdam CR. Is tendon pathology a continuum? A pathology model to explain the clinical presentation of load-induced tendinopathy. Br J Sports Med 2009;43:409-16.

69 Hernandez-Sanchez S, Hidalgo MD, Gomez A. Cross-cultural adaptation of VISA-P score for patellar tendinopathy in spanish population. J Orthop Sports Phys Ther 2011:41:581-91

70 Young MA, Cook JL, Purdam CR, et al. Eccentric decline squat protocol offers superior results at 12 months compared with traditional eccentric protocol for patellar tendinopathy in volleyball players. Br J Sports Med 2005;39:102-5.

71 Kongsgaard M, Kovanen V, Aagaard P, et al. Corticosteroid injections, eccentric decline squat training and heavy slow resistance training in patellar tendinopathy. Scand J Med Sci Sports 2009;19:790-802.

72 Bahr R, Fossan B, Løken S, et al. Surgical treatment compared with eccentric training for patellar tendinopathy (Jumper's Knee). A randomized, controlled trial. J Bone Joint Surg Am 2006;88:1689-98.

73 Everhart JS, Cole D, Sojka JH, et al. Treatment options for patellar tendinopathy: a systematic review. Arthroscopy;2017. In press.

74 Habets B, van Cingel RE. Eccentric exercise training in chronic mid-portion achilles tendinopathy: a systematic review on different protocols. Scand J Med Sci Sports 2015:25:3-15.

75 Filardo G, Di Matteo B, Kon E, et al. Platelet-rich plasma in tendon-related disorders: results and indications. Knee Surg Sports Traumatol Arthrosc. In Press. 2016;2016. 